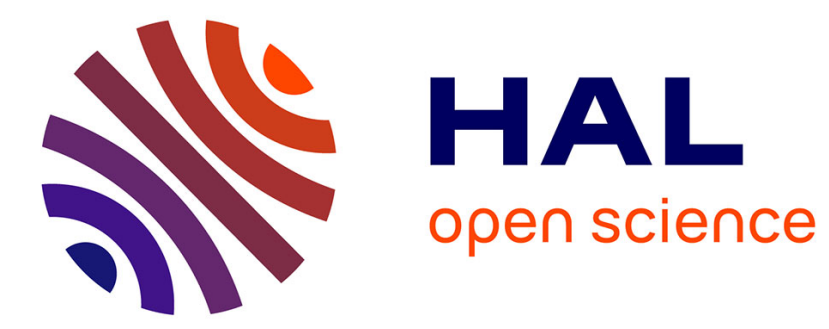

\title{
Numerical investigation of the thermohydraulic behaviour of a complete loop heat pipe
}

\author{
Benjamin Siedel, Valérie Sartre, Frédéric Lefevre
}

\section{To cite this version:}

Benjamin Siedel, Valérie Sartre, Frédéric Lefevre. Numerical investigation of the thermohydraulic behaviour of a complete loop heat pipe. Applied Thermal Engineering, 2013, 61 (2), pp.541-553. 10.1016/j.applthermaleng.2013.08.017 . hal-01025872

\section{HAL Id: hal-01025872 \\ https://hal.science/hal-01025872}

Submitted on 11 Mar 2016

HAL is a multi-disciplinary open access archive for the deposit and dissemination of scientific research documents, whether they are published or not. The documents may come from teaching and research institutions in France or abroad, or from public or private research centers.
L'archive ouverte pluridisciplinaire HAL, est destinée au dépôt et à la diffusion de documents scientifiques de niveau recherche, publiés ou non, émanant des établissements d'enseignement et de recherche français ou étrangers, des laboratoires publics ou privés. 


\title{
Numerical Investigation of the Thermohydraulic Behaviour of a Complete Loop Heat Pipe
}

\author{
Benjamin Siedel, Valérie Sartre*, Frédéric Lefèvre \\ Université de Lyon, CNRS \\ INSA-Lyon, CETHIL UMR5008, F-69621, Villeurbanne, France \\ Université Lyon 1, F-69622, Villeurbanne, France
}

\begin{abstract}
A complete steady-state model has been developed to determine the thermohydraulic behaviour of a loop heat pipe. The model combines a fine discretization of the condenser and the transport lines with a 2-D description of the evaporator. These original features enable to take into account heat losses to the ambient and through the transport lines as well as to evaluate the parasitic heat flux through the wick and the evaporator body. The present numerical simulations may improve the understanding of the physical mechanisms operating in an LHP evaporator, and their coupling with the other parts of the LHP, and provide guidance for the LHP design, aiming to reduce the thermal resistance of the system. The comparison between experimental data of a flat disk-shaped evaporator from the literature and theoretical simulations validates the proposed model. Simulations show the significance of heat conduction through the liquid line. Additionally, results show the major influence of the evaporation coefficient and of the wick thermal conductivity on the LHP operating temperature. When longitudinal heat losses are not significant, the competition between the parasitic heat flux through the wick and the heat transfer to the evaporation zone leads to an extremum for which the operating temperature is maximal. With a thermal conductive evaporator casing, the longitudinal parasitic heat flux strongly influences the LHP operational temperature and the evaporator energy balance.
\end{abstract}

Keywords: Loop Heat Pipe, Modeling, Parametric study, Parasitic heat flux, Evaporation coefficient

\section{Introduction}

Loop Heat Pipes (LHP) are efficient heat transfer devices able to passively transport large amounts of heat and are thus considered as a competitive solution for electronic cooling applications. These two-phase systems, developed in the 1970's in Soviet Union, have already proven their reliable performance in many spatial applications and are today candidate for terrestrial applications.

\footnotetext{
*Corresponding author

Email address: valerie.sartre@insa-lyon.fr (Valérie Sartre)
} 
LHP are mainly made up of an evaporator containing a porous structure where fluid evaporation takes place and of a condenser, both elements being connected by separate vapour and liquid flow lines. The passive fluid circulation, induced by the capillary pressure in the porous media, as well as the use of latent heat of vaporization enable the transport of high amounts of energy, even against adverse gravity effects. Extensive studies have been made to understand the operating principles of such complex systems and to describe the thermal and hydrodynamic couplings of their different elements [1] [2].

In the past decade, a lot of efforts have been devoted to the steady-state modelling of such systems for a better understanding of their operation in order to improve their design. Indeed, the choice of the working fluid and of the loop's geometrical parameters play an important role in the LHP's operation and can lead to unexpected shutdowns or temperature overshoots, putting the electronic device's integrity at risk.

Most of these models can be divided into two categories. A first group of papers presents LHP global operation models discretizing it into several volume elements or based on electrical analogies and describing the whole device as a nodal network. The links between the nodes are represented by thermal resistances and the energy balance equation is applied to each node. Kaya et al. [3] developed a mathematical model based on the steady-state energy balance equations at each component of the LHP. Their simulations show satisfactory accordance with the experimental results. However, at low input powers, some discrepancies are pointed out; authors conclude that the heat exchange with the ambient as well as the pressure drops in the condenser need to be predicted with more accuracy. Adoni et al. [4] developed a steady-state thermohydraulic model to study the effect of compensation chamber hard-filling as well as the influence of the bayonet on the operational characteristics of the LHP. The 1-D steady-state model of Chuang [5] is based on the energy balance equation, thermodynamic relationships and detailed heat transfer and pressure drop calculations in the liquid, vapour and condenser lines. This study describes extensively the LHP operation in gravity-assisted conditions. Yet, heat transfer in the evaporator and the reservoir are not precisely described. Launay et al. [6] presented an analytical LHP global model, based on momentum and energy balance equations and thermodynamic relationships. Two distinct closed-form solutions are found for the various LHP operating modes, based on a previous nodal numerical model. As well as for the other nodal models, the main drawback is an accurate determination of the considered resistances, in particular those describing the thermal links between the saddle, the grooves and the reservoir. Bai et al. [7] also modelled a LHP based on energy conservation laws. Their work shows the influence of a two-layer compound wick and takes into consideration the liquid-vapour shear stresses in the condenser. However, conduction in the transport line walls is neglected and some parameters defining the thermal network of the evaporator have to be experimentally estimated. Such models have the advantage of determining the main operational parameters of the system, based only on the input heat flux, the geometrical characteristics and the ambient conditions. However, heat transfer inside the evaporator structure and the condenser are not precisely described and such simplifying hypotheses can lead to major inaccuracies. 
The second modelling subgroup found in the literature focuses precisely on the thermal links between the various elements of the evaporator and describes the thermal and the hydraulic states of the wick, as well as the characteristics of the evaporation zone. Cao and Faghri [8] obtained analytical solutions of fluid flow and heat transfer in a wick partially heated with the consideration of an evaporating interface. Their work can provide a useful tool to deal with boiling incipience in the porous structure as well as pressure drop in the wick. Figus et al. [9] developed a pore network model to describe the porous structure of the wick. Their work is based on a pore size distribution and shows the fractal displacement of the vapour front inside the wick before the deprime of the LHP. Coquard [10] further developed this model to combine macroscopic transport equations with the pore network approach. Zhao and Liao [11] studied the evaporative heat transfer characteristics from a capillary wick heated with a permeable heating source at the top. The evaporating capillary meniscus was modelled at a pore level in order to determine the heat transfer coefficient. Several operating conditions were observed and a drying of the porous structure occurred as the heat flux increased, eventually leading to the critical heat flux. Ren et al. [12] developed an axisymetric two-dimensional mathematical model of a wick structure nearby a fin and a groove. The capillary-driven convection as well as the influence of the interaction between the flow field and the evaporation interface on the curvature of the menisci have been taken into account in order to study the effect of several parameters such as permeability, porosity and pore radius on the thermal performance. Chernysheva and Maydanik [13] presented a complete 3-D model of a flat evaporator and studied the evaporation rate distribution in the grooves, as well as the start of the wick dry-out. Yet, all these models cannot predict the device operating temperature for a given heat flux and depend on experiments or other models to calculate the reservoir temperature and the temperature of the working fluid entering the reservoir.

The present work is an original way of combining a complete model with a fine description of the evaporator thermal and hydraulic states. Like in the work of Rivière et al. [14], the transport lines and the condenser are discretized and the conservation equations are solved for each subvolume of fluid and each subvolume of tube wall. This is one of the original features of the present model since heat conduction through the tube walls was always neglected in the previous works, although it might have an impact on the LHP operation, in particular for low input powers. Additionally, a 2-D description of the heat and mass transfer in the evaporator is conducted to accurately predict the heat flux distribution in the evaporator casing, in the porous wick and at the liquid-vapour interface.

\section{LHP Global Model Formulation}

\subsection{LHP description and assumptions}

As shown in Figure 1, a LHP consists of an evaporator, a vapour line, a condenser, a liquid line and a reservoir or compensation chamber. In the present work, a flat disk-shaped evaporator is considered. A 
similar approach could be developed for other evaporator designs.

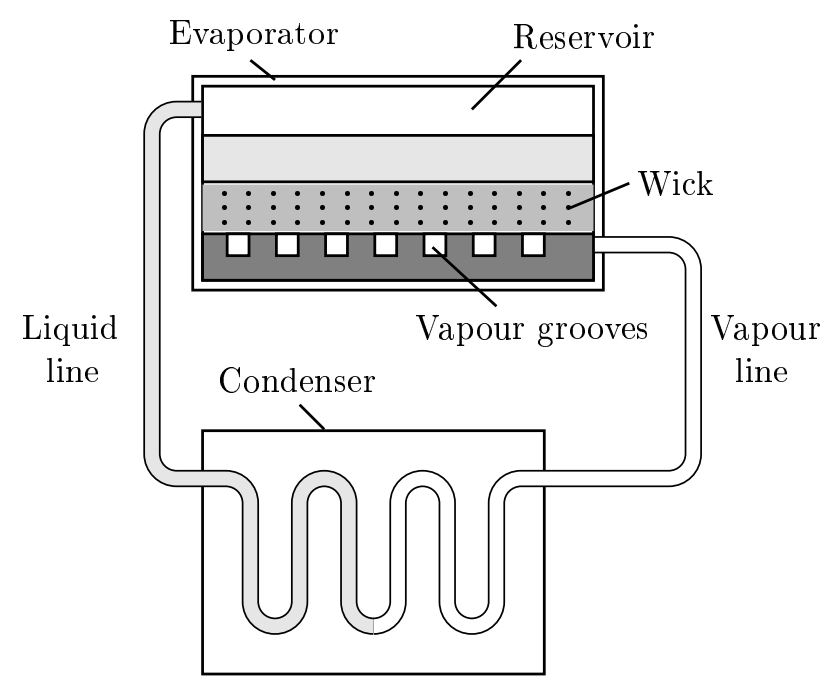

Figure 1: Schematic of a LHP with a flat disk-shaped evaporator

The steady-state model presented here is based on momentum, mass and energy conservation equations and on thermodynamic relationships. The major assumptions are:

(a) The loop operates at steady-state.

(b) The wick is fully saturated of liquid and evaporation takes place at the liquid-vapour interface in the vapour grooves.

(c) The fluid is considered incompressible because its velocity is much lower than the sound speed in the same medium in a typical LHP operation.

(d) The temperature difference between the inner and the outer surfaces of the tubes is neglected.

(e) The heat sink temperature and the external heat transfer coefficient are considered uniform along the condenser.

\subsection{Vapour line, liquid line and condenser}

The condenser and the transport lines are discretized into small elements of volume as shown in Figure 2 ,

To determine the wall temperature $T_{\text {wall }}$, the energy balance equation is written, neglecting the radial conduction in the wall:

$$
\begin{aligned}
\lambda_{\text {wall }} A_{\text {wall }} \frac{\mathrm{d}^{2} T_{\text {wall }}}{\mathrm{d} z^{2}}= & h_{\text {out }} p_{\text {out }}\left(T_{\text {wall }}-T_{\text {out }}\right) \\
& +h_{\text {in }} p_{\text {in }}\left(T_{\text {wall }}-T_{\mathrm{f}}\right)
\end{aligned}
$$




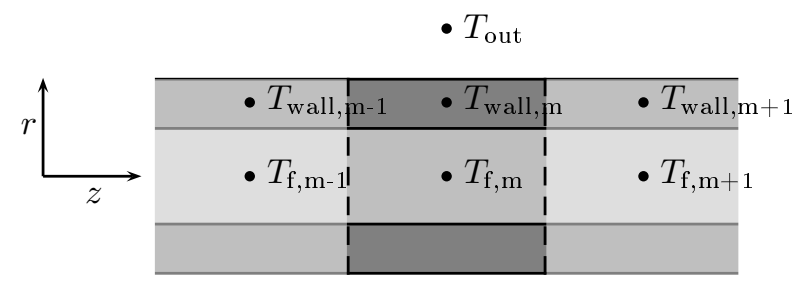

Figure 2: Transport lines discretization

where $T_{\text {out }}$ is the ambient or heat sink temperature, $h_{\text {out }}$ and $h_{\text {in }}$ are the heat transfer coefficients outside and inside the tube respectively, $p$ is the perimeter and $A$ the cross-sectional area of the tube.

In single-phase flow, the fluid temperature $T_{\mathrm{f}}$ is given by:

$$
\frac{\mathrm{d} T_{\mathrm{f}}}{\mathrm{d} z}=\frac{h_{\text {in }} p_{\text {in }}\left(T_{\text {wall }}-T_{\mathrm{f}}\right)}{\dot{m}_{\mathrm{f}} c_{\mathrm{p}, \mathrm{f}}}
$$

In two-phase flow, the fluid is at saturation temperature $T_{\text {sat }}$ and the variation of the liquid mass flow rate is expressed by:

$$
\frac{\mathrm{d} \dot{m}_{1}}{\mathrm{~d} z}=\frac{h_{\text {in }} p_{\text {in }}\left(T_{\text {wall }}-T_{\mathrm{f}}\right)}{h_{\mathrm{lv}}}
$$

The saturation temperature is determined using the Clausius-Clapeyron relation:

$$
\frac{\partial T}{\partial P}=\frac{T\left(1 / \rho_{\mathrm{v}}-1 / \rho_{\mathrm{l}}\right)}{h_{\mathrm{lv}}}
$$

Knowing the phase change mass flow rate along the tubes, it is possible to determine the vapour quality for each element:

$$
x=\frac{\dot{m}_{\mathrm{v}}}{\dot{m}_{1}+\dot{m}_{\mathrm{v}}}
$$

Pressure drops are calculated assuming smooth tubes with:

$$
\left(\frac{\mathrm{d} P}{\mathrm{~d} z}\right)_{\text {tot }}=\left(\frac{\mathrm{d} P}{\mathrm{~d} z}\right)_{\text {fric }}+\left(\frac{\mathrm{d} P}{\mathrm{~d} z}\right)_{\text {static }}+\left(\frac{\mathrm{d} P}{\mathrm{~d} z}\right)_{\text {mom }}
$$

where the frictional pressure drop is determined using the Müller-Steinhagen and Heck correlation [15]:

$$
\begin{aligned}
\left(\frac{\mathrm{d} P}{\mathrm{~d} z}\right)_{\text {fric }}= & \left(\left(\frac{\mathrm{d} P}{\mathrm{~d} z}\right)_{1}+2\left[\left(\frac{\mathrm{d} P}{\mathrm{~d} z}\right)_{\mathrm{v}}-\left(\frac{\mathrm{d} P}{\mathrm{~d} z}\right)_{1}\right] x\right)(1-x)^{\frac{1}{3}} \\
& +\left(\frac{\mathrm{d} P}{\mathrm{~d} z}\right)_{\mathrm{v}} x^{3}
\end{aligned}
$$

Assuming the vapour and liquid velocities are equal, the void fraction is given by:

$$
\varepsilon=\left[1+\frac{1-x}{x}\left(\frac{\rho_{\mathrm{v}}}{\rho_{1}}\right)\right]^{-1}
$$

As suggested by Thome [16], the two-phase flow is characterized considering a homogeneous pseudo-fluid that obeys the conventional equations for single-phase fluids and which properties correspond to the averaged 
properties of both the liquid and vapour phase. In that case, the homogeneous fluid density is defined as:

$$
\rho_{\mathrm{h}}=\rho_{\mathrm{l}}(1-\varepsilon)+\rho_{\mathrm{v}} \varepsilon
$$

The momentum pressure gradient per unit length is then:

$$
\left(\frac{\mathrm{d} P}{\mathrm{~d} z}\right)_{\mathrm{mom}}=\frac{\dot{m}_{\mathrm{f}}}{A} \frac{\mathrm{d}}{\mathrm{d} z}\left(\frac{\dot{m}_{\mathrm{f}}}{\rho_{\mathrm{h}} A}\right)
$$

whereas the hydrostatic term is defined by:

$$
\left(\frac{\mathrm{d} P}{\mathrm{~d} z}\right)_{\text {static }}=\rho_{\mathrm{h}} g \frac{\mathrm{d} H}{\mathrm{~d} z}
$$

where $H$ is the altitude of the considered element.

The heat transfer coefficient with the ambient is given by Churchill and Chu [17] for free convection on the surface of an isothermal cylinder:

$$
h_{\mathrm{amb}}=\frac{\lambda_{\mathrm{air}}}{D_{\mathrm{out}}}\left[0.60+\frac{0.387 R a_{\mathrm{D}}^{\frac{1}{6}}}{\left(1+(0.559 / P r)^{\frac{9}{16}}\right)^{\frac{8}{27}}}\right]^{2}
$$

This correlation is valid for Rayleigh numbers $R a_{\mathrm{D}}$ lower than $10^{12}$.

Inside the tube, in the case of single-phase laminar flow $\left(R e_{\mathrm{D}}<2300\right)$, the fully-developed state is described by $G z_{\mathrm{D}} \leqslant 20$, where the Graetz number is:

$$
G z_{\mathrm{D}}=\frac{D}{z} \operatorname{Re} e_{\mathrm{D}} \operatorname{Pr}
$$

The heat transfer between the fluid and the tube wall is then given by [18]:

$$
\begin{array}{rlrl}
G z_{\mathrm{D}} & \leqslant 20 & h_{\text {in }}=4.36 \frac{\lambda_{\mathrm{l}}}{D_{\text {in }}} \\
G z_{\mathrm{D}}>20 & h_{\text {in }}=1.86\left(\frac{R e_{\mathrm{D}} P r}{L / D}\right)^{\frac{1}{3}}\left(\frac{\mu_{\mathrm{f}, \mathrm{T}=\mathrm{T}_{\mathrm{f}}}}{\mu_{\mathrm{f}, \mathrm{T}=\mathrm{T}_{\text {wall }}}}\right)^{0.14} \frac{\lambda_{\mathrm{l}}}{D_{\text {in }}}
\end{array}
$$

For a turbulent flow, the entrance length is much smaller and fully developed conditions are assumed:

$$
h_{\text {in }}=0.023 \frac{\lambda_{\mathrm{f}}}{D_{\text {in }}} \operatorname{Re}_{\mathrm{D}}^{\frac{4}{5}} \operatorname{Pr}^{\frac{1}{3}}
$$

In the case of two-phase flow, a fine modelling of the heat transfer associated with condensation can be found in the work of Miscevic et al. [19]. This model takes into account the transient behaviour of the liquid shape inside the tube due to the capillary effects. However, such an approach is difficult to introduce in a complete steady-state model of a LHP. Thus, another approach is followed: the Soliman's modified Froude number determines the flow regime as a function of the dimensionless liquid Reynolds and Galileo numbers [20]:

$$
\begin{array}{ll}
\text { if } R e_{1}<1250 & F r=0.025 \frac{R e_{1}^{1.59}}{G a^{0.5}}\left(\frac{1+1.09 \chi_{\mathrm{tt}}^{0.039}}{\chi_{\mathrm{tt}}}\right)^{1.5} \\
\text { if } R e_{1}>1250 & F r=1.26 \frac{R e_{1}^{1.04}}{G a^{0.5}}\left(\frac{1+1.09 \chi_{\mathrm{tt}}^{0.039}}{\chi_{\mathrm{tt}}}\right)^{1.5}
\end{array}
$$




$$
\text { with } G a=\frac{g D^{3} \rho_{1}^{2}}{\mu_{1}^{2}} \text { and } R e_{1}=\frac{4 \dot{m}_{\mathrm{tot}}(1-x)}{\pi D \mu_{1}}
$$

and where $\chi_{\mathrm{tt}}$ is the Martinelli parameter defined as [21]:

$$
\chi_{\mathrm{tt}}=\sqrt{\frac{(\mathrm{d} P / \mathrm{d} z)_{1}}{(\mathrm{~d} P / \mathrm{d} z)_{\mathrm{v}}}} \approx\left(\frac{1-x}{x}\right)^{0.9}\left(\frac{\rho_{\mathrm{v}}}{\rho_{\mathrm{l}}}\right)^{0.5}\left(\frac{\mu_{\mathrm{l}}}{\mu_{\mathrm{v}}}\right)^{0.1}
$$

For Froude numbers lower than 10, the flow is assumed stratified and the correlation of Jaster and Kosky [22] is used to determine the heat transfer coefficient:

$$
h_{\text {in }}=0.728 \varepsilon^{\frac{3}{4}}\left(\frac{g h_{\mathrm{lv}} \lambda_{1}^{3}\left(\rho_{1}-\rho_{\mathrm{v}}\right) \rho_{1}}{D_{\text {in }} \mu_{1}\left(T_{\mathrm{f}}-T_{\text {wall }}\right)}\right)^{0.25}
$$

The flow is assumed annular otherwise and the correlation given by Akers et al. [23] is used:

$$
\begin{array}{ll}
\text { if } R e<5 \times 10^{5} & h_{\text {in }}=5.03 \frac{\lambda_{\mathrm{f}}}{D_{\text {in }}} \operatorname{Re}_{\mathrm{eq}}^{\frac{1}{3}} \operatorname{Pr}_{1}^{\frac{1}{3}} \\
\text { if } R e>5 \times 10^{5} & h_{\text {in }}=0.0265 \frac{\lambda_{\mathrm{f}}}{D_{\text {in }}} \operatorname{Req}^{\frac{4}{5}} \operatorname{Pr}_{1}^{\frac{1}{3}}
\end{array}
$$

where the equivalent Reynolds number for two-phase flow $R e_{\text {eq }}$ is determined from an equivalent mass flow rate:

$$
\dot{m}_{\mathrm{eq}}=\dot{m}_{\mathrm{tot}}\left[(1-x)+x\left(\frac{\rho_{\mathrm{l}}}{\rho_{\mathrm{v}}}\right)^{1 / 2}\right]
$$

\subsection{Determination of the mass flow rate}

In a first approach, the heat losses to the ambient, the heat transferred by conduction through the transport lines as well as the sidewall parasitic heat losses are not taken into account. A simplified global energy balance of the evaporator gives then the following equation:

$$
Q_{\text {in }}=Q_{\mathrm{ev}}+Q_{\mathrm{sen}}+Q_{\mathrm{sub}}
$$

where $Q_{\text {in }}$ is the heat dissipated by the device that has to be cooled by the LHP. The terms on the right-hand side of the equation correspond to the latent heat of vaporization of the fluid at the wick surface, the sensible heat provided to the liquid in the wick, and the subcooling due to the return of liquid from the condenser. Considering the relationships between these heat transfer rates and the mass flow rate inside the LHP:

$$
\begin{gathered}
Q_{\mathrm{ev}}=\dot{m}_{\mathrm{f}} h_{\mathrm{lv}} \\
Q_{\mathrm{sen}}=\dot{m}_{\mathrm{f}} c_{\mathrm{p}, \mathrm{l}}\left(T_{\mathrm{gr}}-T_{\mathrm{res}}\right) \\
Q_{\mathrm{sub}}=\dot{m}_{\mathrm{f}} c_{\mathrm{p}, 1}\left(T_{\mathrm{res}}-T_{\text {res,in }}\right)
\end{gathered}
$$

with $T_{\mathrm{gr}}, T_{\text {res }}$ and $T_{\text {res,in }}$ the temperatures of the fluid inside the grooves, in the reservoir and entering the reservoir, respectively. The pressure in the reservoir $P_{\text {res }}$ is calculated by the transport lines model and sets 
the saturation temperature of the reservoir $T_{\text {res }} . T_{\text {res,in }}$ is also determined using the transport lines model while the value of $T_{\mathrm{gr}}$ is solved using a 2-D model described in the next section. The mass flow rate is then calculated by combining Eq. (25) to (28):

$$
\dot{m}_{\mathrm{f}}=\frac{Q_{\mathrm{in}}}{h_{\mathrm{lv}}+c_{\mathrm{p}, \mathrm{l}}\left(T_{\mathrm{gr}}-T_{\mathrm{res}, \text { in }}\right)}
$$

\subsection{Heat and mass transfer in the wick}

In the literature, LHP models usually consider heat transfer through the wick as a uniform 1-D conductiveconvective transfer, assuming an equivalent thermal conductivity of the wick. In order to determine accurately heat and mass transfer in the porous media, a 2-D finite difference description of the wick is undertaken in this model. As shown in Figure 3, a small element of the evaporator has been chosen for this study, located between the centre of the vapour groove and the centre of the nearby fin, between the liquid-vapour interface in the reservoir and the upper surface of the evaporator wall. The following assumptions are made:

(a) Heat and mass transfer are two-dimensional.

(b) Evaporation only occurs at the surface of the porous structure nearby the vapour groove.

(c) Local liquid and wick temperatures are considered equal.

(d) Gravitational effects are neglected.

(e) Heat losses to the ambient, through the transport lines and parasitic heat flux through the evaporator casing are neglected.

(f) The reservoir contains a two-phase fluid. As it is located above the evaporator, a height of liquid $H_{1}$ sits on the top of the wick structure.

Based on the total fluid inventory of the LHP, assuming the wick is fully saturated of liquid and calculating the void fraction along the transport lines and the condenser, it is possible to determine the height of liquid $H_{1}$ in the reservoir.

To describe the liquid flow inside the porous structure, Darcy's law is considered:

$$
u=-\frac{K_{\mathrm{w}}}{\mu_{\mathrm{l}}} \nabla P
$$

where $u$ is the liquid velocity and $K_{\mathrm{w}}$ is the wick permeability, expressed by the Carman-Koseny relationship for a sintered structure [24]:

$$
K_{\mathrm{w}}=\frac{r_{\mathrm{p}}^{2} \varepsilon^{3}}{37.5(1-\varepsilon)^{2}}
$$

where $r_{\mathrm{p}}$ is the pore radius and $\varepsilon$ is the porosity of the wick. Considering the continuity equation and Eq. (30), the pressure field in the wick can be written:

$$
\nabla^{2} P=0
$$




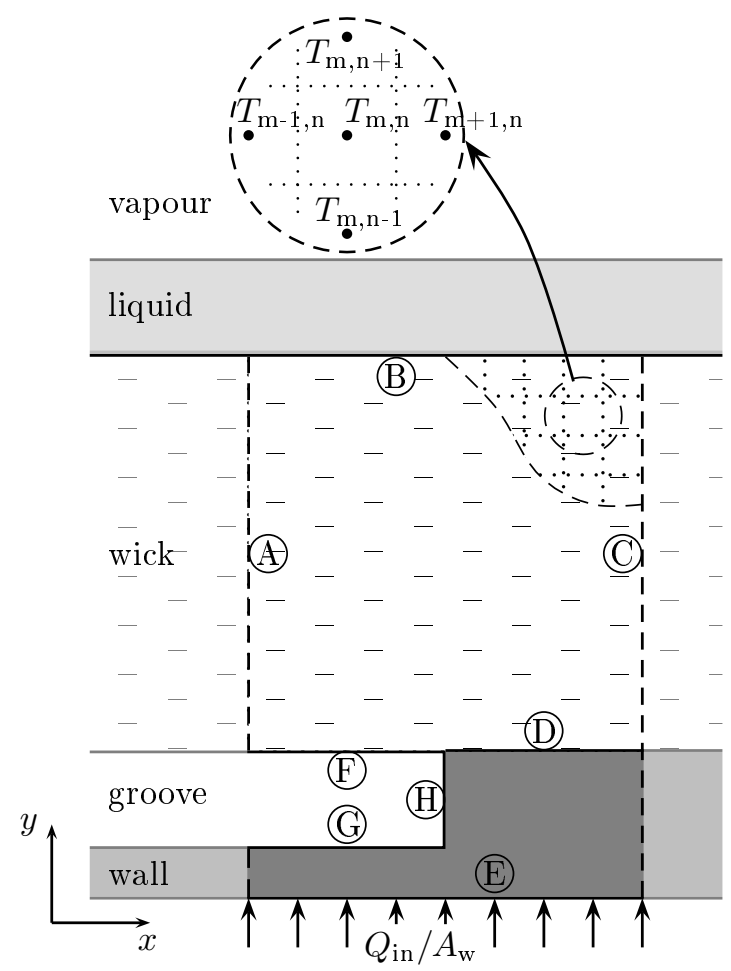

Figure 3: Heat and mass transfer in the wick

The following boundary conditions are considered at the boundaries A to F:

$$
\text { A and C: } \begin{array}{rlrl}
\frac{\partial P}{\partial x} & =0 \\
\text { B: } & \frac{\partial P}{\partial y} & =0 \\
\text { D: } & P & =P_{\text {res }} \\
\text { F } & P &
\end{array}
$$

As frontiers $\mathrm{A}$ and $\mathrm{C}$ are symmetry axes, the liquid velocities have no $x$-component. At the boundary $\mathrm{D}$, the impermeability condition is applied. The pressure in the groove is set by the thermodynamic state of the latter $P_{\mathrm{gr}}=P_{\mathrm{sat}}\left(T_{\mathrm{gr}}\right)$.

In order to calculate the temperature field, conduction in the porous structure and convective heating of the liquid flowing through the wick are considered, leading to the following energy equation:

$$
\lambda_{\mathrm{eff}} \nabla^{2} T=\rho_{\mathrm{l}} c_{\mathrm{p}, 1} \nabla(u T)
$$

Several models can be found in the literature to estimate the effective thermal conductivity $\lambda_{\text {eff }}$ of a sintered porous structure filled with liquid. Based on the work of Singh et al. [25] who compared their experimental results for monoporous copper with several correlations, a relationship based on Alexander's 
work is used in the present study:

$$
\lambda_{\text {eff }}=\lambda_{1}\left(\frac{\lambda_{1}}{\lambda_{\mathrm{w}}}\right)^{-(1-\varepsilon)^{0.59}}
$$

The boundary conditions are as follows:

$$
\begin{array}{rlrl}
\text { A and C: } & \frac{\partial T}{\partial x} & =0 \\
& \text { B: } & -\lambda_{\text {eff }} \frac{\partial T}{\partial y} & =\frac{\lambda_{1}}{H_{1}}\left(T-T_{\text {res }}\right) \\
\text { E: } & -\lambda_{\mathrm{ev}} \frac{\partial T}{\partial y}=\frac{Q_{\mathrm{in}}}{A_{\mathrm{w}}} \\
\text { F: } & h_{\mathrm{ev}}\left(T-T_{\mathrm{gr}}\right)=-h_{\mathrm{lv}} u_{\mathrm{y}} \rho_{\mathrm{l}} \\
\text { G: } & -\lambda_{\mathrm{ev}} \frac{\partial T}{\partial y}=h_{\mathrm{gr}}\left(T-T_{\mathrm{gr}}\right) \\
\text { H: } & \lambda_{\mathrm{ev}} \frac{\partial T}{\partial x} & =h_{\mathrm{gr}}\left(T-T_{\mathrm{gr}}\right)
\end{array}
$$

The sides of the considered region (dashed lines) are assumed adiabatic because of the symmetry. The thickness of the liquid layer in the reservoir is supposed to be small enough to neglect the convective heat transfer. Thus a Fourier boundary condition is applied with a heat transfer coefficient defined by the 1-D heat conduction in the liquid. The convective heat transfer coefficient in the groove $h_{\mathrm{gr}}$ is set to a constant value considering natural convection. At the outer wall surface, a fixed heat flux $Q_{\mathrm{in}} / A_{\mathrm{w}}$ is applied, where $A_{\mathrm{w}}$ is the cross-sectional area of the wick.

A thermal contact resistance between the porous structure and the evaporator wall has to be considered. Choi et al.[26] studied the thermal characteristics of several vapor channel geometries. Based on their work, a constant good thermal contact is assumed and the contact resistance is equal to $5.10^{-5} \mathrm{~K} \cdot \mathrm{m}^{2} \cdot \mathrm{W}^{-1}$.

Evaporation occurs at the wick surface in contact with the vapour groove. The evaporation heat transfer coefficient is calculated with the following relationship [27] :

$$
h_{\mathrm{ev}}=\frac{2 a_{\mathrm{ev}}}{2-a_{\mathrm{ev}}} \frac{\rho_{\mathrm{v}} h_{\mathrm{lv}}^{2}}{T_{\mathrm{sat}}}\left(\frac{2 \pi \bar{R} T_{\mathrm{sat}}}{\bar{M}}\right)^{-0.5}\left(1-\frac{P_{\mathrm{sat}}}{2 \rho_{\mathrm{v}} h_{\mathrm{lv}}}\right)
$$

where $a_{\mathrm{ev}}$ is the evaporation coefficient. In the case of the evaporation of a thin liquid film, the evaporation coefficient is defined as the ratio of the actual evaporation rate to a theoretical maximal phase change rate. A coefficient equal to unity describes a perfect evaporation while a lower value represents an incomplete evaporation. In the case of water, values varying from 0.01 to 1 are suggested in the literature [28].

\subsection{Solving procedure}

The complete solving procedure is presented in Figure 4 For a given heat flux, the thermal and hydraulic states are initialized using the analytical model of Launay et al. [6]. 


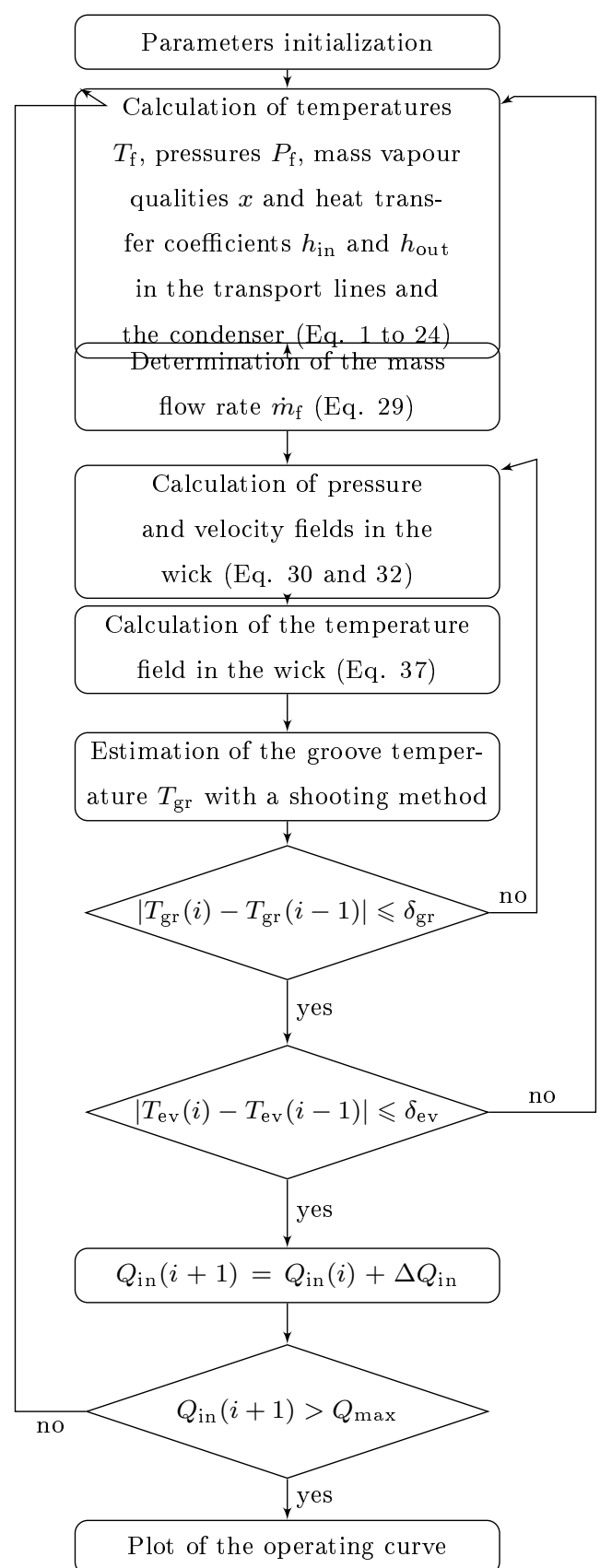

Figure 4: Solving algorithm flowchart 
First, the transport lines and the condenser are computed. The input parameters are the groove temperature $T_{\mathrm{gr}}$, the maximum wall temperature in the evaporator $T_{\mathrm{ev}}$, the reservoir temperature $T_{\mathrm{res}}$ and the mass flow rate $\dot{m}_{\mathrm{f}}$. The pressure at the entrance of the vapour line is the saturation pressure corresponding to the vapour temperature in the groove $T_{\mathrm{gr}}$. The tube wall temperatures are determined solving Equation (1) with the Thomas algorithm (also known as Tridiagonal Matrix Algorithm), using $T_{\text {ev }}$ and $T_{\text {res }}$ at each end of the transport lines as boundary conditions. Then the fluid pressures $P_{\mathrm{f}}$, the mass vapour qualities $x$, the inner heat transfer coefficients $h_{\text {in }}$ as well as the fluid temperatures $T_{\mathrm{f}}$ are computed step by step with an iterative method, using the approach presented in 2.2. until each calculated parameter has converged. The energy balance at the evaporator enables to recalculate the mass flow rate $\dot{m}_{\mathrm{f}}$ using Equation (29).

The model describing heat and mass transfer in the evaporator is then computed. The input parameters are the mass flow rate $\dot{m}_{\mathrm{f}}$, the reservoir pressure $P_{\text {res }}$ and its corresponding saturation temperature $T_{\text {res }}$

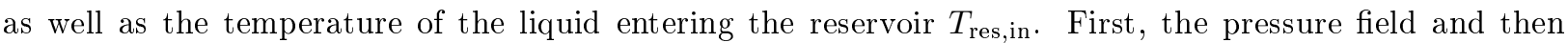
the temperature field in the porous structure are calculated, using the Thomas algorithm alternatively in both directions. The groove temperature $T_{\mathrm{gr}}$ is estimated with a shooting method. $T_{\mathrm{gr}}$ is iteratively modified until the heat flux in the evaporation zone is equal to $\dot{m}_{\mathrm{f}} h_{\mathrm{lv}}$. When the errors on $T_{\mathrm{gr}}$ and $T_{\mathrm{ev}}$ are negligible, the complete thermo-hydraulic state of the LHP is considered determined and another input heat flux is computed, until the complete characteristic curve is calculated. The computational time required to calculate a 14-points characteristic curve is of about $8 \mathrm{~min}$.

\subsection{Modelling of the heat transfer through the casing}

The model presented in Section 2.4 does not take into account the heat losses from the evaporator to the ambient nor the thermal conduction through the evaporator casing to the reservoir and to the transport lines. In order to introduce these parameters, Eq. (25), (29) and (41) become respectively:

$$
\begin{aligned}
Q_{\text {in }}= & Q_{\text {tube }, \mathrm{v}}+Q_{\text {tube }, 1}+Q_{\mathrm{ev}}+Q_{\mathrm{sen}}+Q_{\mathrm{sub}}+Q_{\mathrm{amb}} \\
& \dot{m}_{\mathrm{f}}=\frac{Q_{\mathrm{in}}-Q_{\mathrm{tube}, \mathrm{v}}-Q_{\mathrm{tube}, \mathrm{l}}-Q_{\mathrm{amb}}}{h_{\mathrm{lv}}+c_{\mathrm{p}, \mathrm{l}}\left(T_{\mathrm{gr}}-T_{\mathrm{res}, \text { in }}\right)} \\
& -\lambda_{\mathrm{ev}} \frac{\partial T}{\partial y}=\left(Q_{\mathrm{in}}-Q_{\mathrm{tube}, \mathrm{v}}-Q_{\mathrm{wall}}\right) \frac{1}{A_{\mathrm{w}}}
\end{aligned}
$$

where $Q_{\text {tube,v }}$ and $Q_{\text {tube,l }}$ are the parts of heat flow transferred by conduction to the vapour line from the evaporator and to the liquid line from the reservoir, respectively. They are determined with the transport lines model considering the temperature gradient of the tube walls at the entrance of the vapour line and at the exit of the liquid line. Since a 2-D model cannot precisely consider $Q_{\text {tube,v }}$, its value is subtracted directly from the total heat load $Q_{\text {in }}$ in Eq. (48). $Q_{\text {amb }}$ is equal to the heat losses to the ambient. $Q_{\text {wall }}$ is the part of the heat transferred through the evaporator sidewall that is not given back to the wick due to convective heat transfer between the liquid in the porous media and the sidewall. $Q_{\text {wall }}$ is referred to as the 
longitudinal heat losses in the following. A part of $Q_{\text {wall }}$ is then dissipated to the ambient while the rest is given to the reservoir. To take into account heat losses, the 2-D model presented in Figure 3 is computed using Eq. (46) to (48).

The estimation of both $Q_{\mathrm{amb}}$ and $Q_{\text {wall }}$ requires an additional model. Obviously, a 3-D description of the entire evaporator would give the most accurate results. However, in order to reduce the computational time, a 2-D approach has been chosen in this study (Fig. (5). The number of grooves to be modelled is determined so that edge effects are negligible at the centre of the groove located at the opposite side of the sidewall. The dashed line is thus assumed to be an adiabatic boundary. The vapour zone in the reservoir is considered at a homogeneous temperature $T_{\text {res }}$. Contrarily to the model presented in Figure 3, the 2-D heat conduction equation is solved in the liquid to take into account the heat transfer with the casing. We assume that the liquid thickness $H_{1}$ in the reservoir is small enough to neglect convection phenomena inside the liquid. The liquid-vapour interface $\mathrm{I}$ is set to $T_{\text {res }}$. A perfect contact is assumed between the body of the evaporator and the wick.

At the contact surface between the evaporator casing and the vapour, two distinct situations may occur: if the vapour is colder than the wall, the liquid evaporates in the reservoir whereas condensation of the vapour occurs otherwise. In the case of evaporation in the reservoir, heat transfer is greatly enhanced at the triple line, at the contact between the wall and the liquid-vapour interface. The heat transfer can be determined using an evaporation heat transfer coefficient calculated with Eq. (45). In this situation, the convective heat transfer between the wall and the vapour is neglected and an adiabatic boundary is assumed. The heat dissipated from the reservoir top surface to the ambient $Q_{\mathrm{amb}, \mathrm{top}}$ as well as the heat losses through the liquid line are also due to the heat conduction in the casing. Thus, the boundary condition $\mathrm{J}$ is:

$$
-\lambda_{\mathrm{ev}} \frac{\partial T}{\partial y}=\frac{4\left(Q_{\mathrm{amb}, \mathrm{top}}+Q_{\mathrm{tube}, \mathrm{l}}\right)}{\pi\left(D_{\mathrm{wall}}^{2}-D_{\mathrm{w}}^{2}\right)}
$$

In the event of condensation of the vapour on the reservoir wall, the heat transfer along the wall is fixed to $10^{4} \mathrm{~W} \cdot \mathrm{m}^{-2} \cdot \mathrm{K}^{-1}$, based on Nusselt's filmwise condensation theory [18]. With such a high heat transfer coefficient, the heat dissipated from the reservoir top surface and through the liquid line is coming from the reservoir and not from the casing, as in the previous case. Therefore, the boundary $\mathrm{J}$ is considered adiabatic in that case.

The boundary conditions (33) to (36) and (42) to (44) are similar to those of the model presented in Figure 3. On the evaporator bottom surface, a constant heat flux is set:

$$
-\lambda_{\mathrm{ev}} \frac{\partial T}{\partial y}=\frac{Q_{\mathrm{in}}-Q_{\text {tube, }}}{A_{\mathrm{w}}}
$$

As shown in Figure , a part of the heat conducted through the evaporator body $Q_{\text {wall }}$ is dissipated to the ambient while the rest is transported to the reservoir and through the boundary J. $Q_{\text {amb }}$ is calculated considering free convection and radiation around the evaporator body, knowing the temperature profile on 


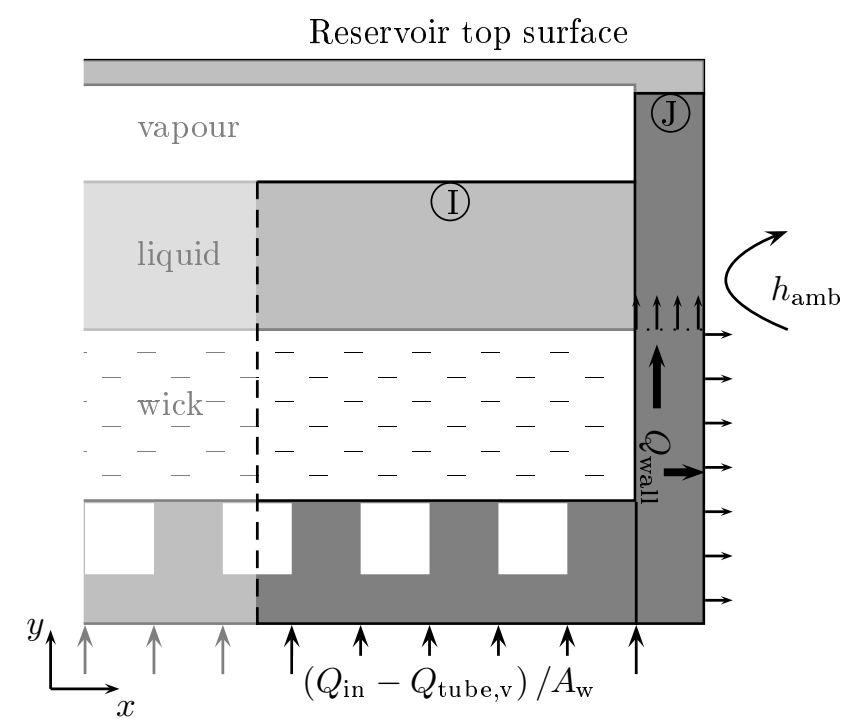

Figure 5: Heat transfer to the ambient and through the body

the side of the evaporator and assuming a reservoir top surface temperature equal to $T_{\text {res }}$. The model presented in Fig. 3 gives the mean temperature of the evaporator $T_{\mathrm{ev}}$, while the maximum temperature $T_{\mathrm{ev}, \max }$ located in the centre of the evaporator can be obtained by the model presented in Fig. 5 ,

\section{Model validation}

The model predictions are compared to experimental data from the literature for the purpose of validation. Singh et al. studied the operational characteristics of a flat disk-shaped evaporator LHP in horizontal configuration, using water as working fluid [29]. The $3 \mathrm{~mm}$ thick porous wick is made of sintered nickel, with $75 \%$ porosity and $3-5 \mu \mathrm{m}$ mean pore radius. The porous wick is embedded in a pure copper evaporator $\left(\lambda=398 W \cdot m^{-1} \cdot K^{-1}\right), 10 \mathrm{~mm}$ thick and with an active zone diameter of $30 \mathrm{~mm}$. The vapour and liquid lines, of $2 \mathrm{~mm}$ internal diameter, are $150 \mathrm{~mm}$ and $290 \mathrm{~mm}$ long respectively and also made of pure copper. The fin-and-tube condenser, $50 \mathrm{~mm}$ long, dissipates heat by forced convection of air at ambient temperature (i.e. $22^{\circ} \mathrm{C}$ ). A straight-tube equivalent condenser is simulated with an external heat transfer coefficient arbitrarily chosen equal to $2.6 \mathrm{~kW} \cdot \mathrm{m}^{-2} \cdot \mathrm{K}^{-1}$, according to the experimental results, considering an outside diameter of $2.4 \mathrm{~mm}$ for the tubes. Fifteen grooves with a square cross-sectional area of $1 \mathrm{~mm}^{2}$ are modelled and the wall thickness of the evaporator is taken equal to $2 \mathrm{~mm}$. A reservoir height of $4 \mathrm{~mm}$ is chosen to provide the volume necessary for the total fluid mass of $5 \mathrm{~g}$ in the entire heat input range. An evaporation coefficient equal to 0.02 is chosen to fit the experimental data. Since the loop was thermally insulated with fibreglass, heat losses to the ambient are neglected. Furthermore, as an O-ring seal prevents heat from being conducted through the evaporator body, longitudinal heat losses are also neglected. 
The comparison between the experimental data and the calculated temperatures of the evaporator wall is shown in Figure 6. A good agreement is obtained for the entire input power range, although for high heat loads the model tends to predict higher evaporator temperatures than the experimental data. The experimental data scattering shows some non repeatability of the LHP operation. The mean error between the simulation and experimental data is of $2.6 \mathrm{~K}$, which is on the same order of magnitude as the experimental results scattering.

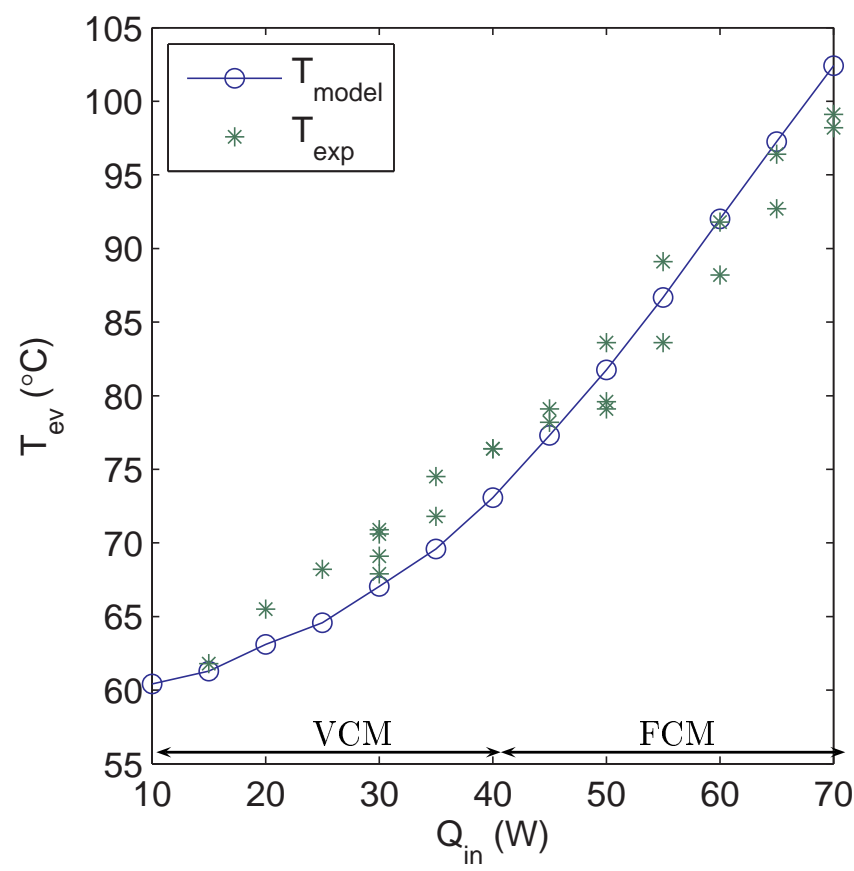

Figure 6: Comparison between the model and data from Singh et al. [29]

One can clearly see the two distinct operating modes, known as variable conductance mode (VCM), up to about $40 \mathrm{~W}$, where the two-phase length can vary in the condenser, and the fixed conductance mode (FCM) for which the end of the condensation takes place at the very end of the condenser or even in the liquid line. In the latter, the evaporator temperature varies almost linearly with the heat load and at a higher rate than in VCM.

The evaporation coefficient can have a significant influence on the heat transfer in the wick close to the vapour grooves and the fins. Indeed, a low evaporation coefficient moderates the evaporation rate and flattens the evaporation rate profile at the wick surface in contact with the groove. Figure 7 presents the effect of the evaporation coefficient on the evaporator temperature $T_{\mathrm{ev}}$. Decreasing $a_{\mathrm{ev}}$ strongly affects the LHP operating temperature. Indeed, since the evaporation rate is limited, a large amount of heat is conducted 
through the wick and through the transport lines. The determination of the evaporation coefficient is thus a key parameter of the loop heat pipe modelling, but presently its value is not well referenced in the literature. In the following parametric study, simulations will be conducted with a constant coefficient equal to 0.02 based on the validation results. Additionally, to ensure a good evaporator temperature homogeneity, a grooved wall made of copper will be simulated $\left(\lambda=398 \mathrm{~W} \cdot \mathrm{m}^{-1} \cdot \mathrm{K}^{-1}\right)$.

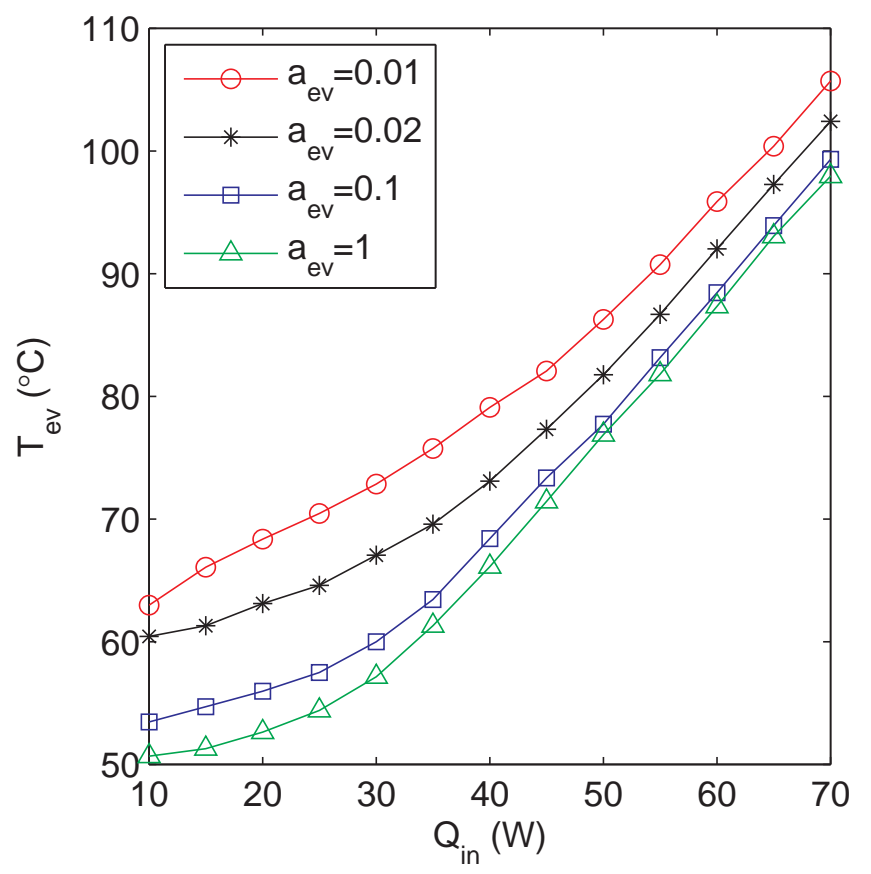

Figure 7: Influence of the evaporation coefficient on the LHP operating temperature

\section{Results and discussion}

\subsection{Thermal conduction in the vapour and liquid lines}

Figure 8 presents the comparison of different materials for the vapour and liquid lines and the condenser, neglecting the longitudinal heat losses $Q_{\text {wall }}$ as well as heat losses from the evaporator to the ambient $Q_{\mathrm{amb}}$. In variable conductance mode, high conductive materials lead to better LHP performance. Indeed, a larger part of the heat to be dissipated is conducted through the lines and this leads to a cooling of the LHP, since a higher temperature of the transport line wall induces more heat losses to the ambient. At high input powers the difference is not significant and the heat conduction through the transport lines does not strongly influence the LHP operation.

At low input powers, the mass flow rate in the tubes is extremely low. In addition, a large part of the condenser is filled with liquid and operates as a subcooler. Therefore, the liquid temperature at the 


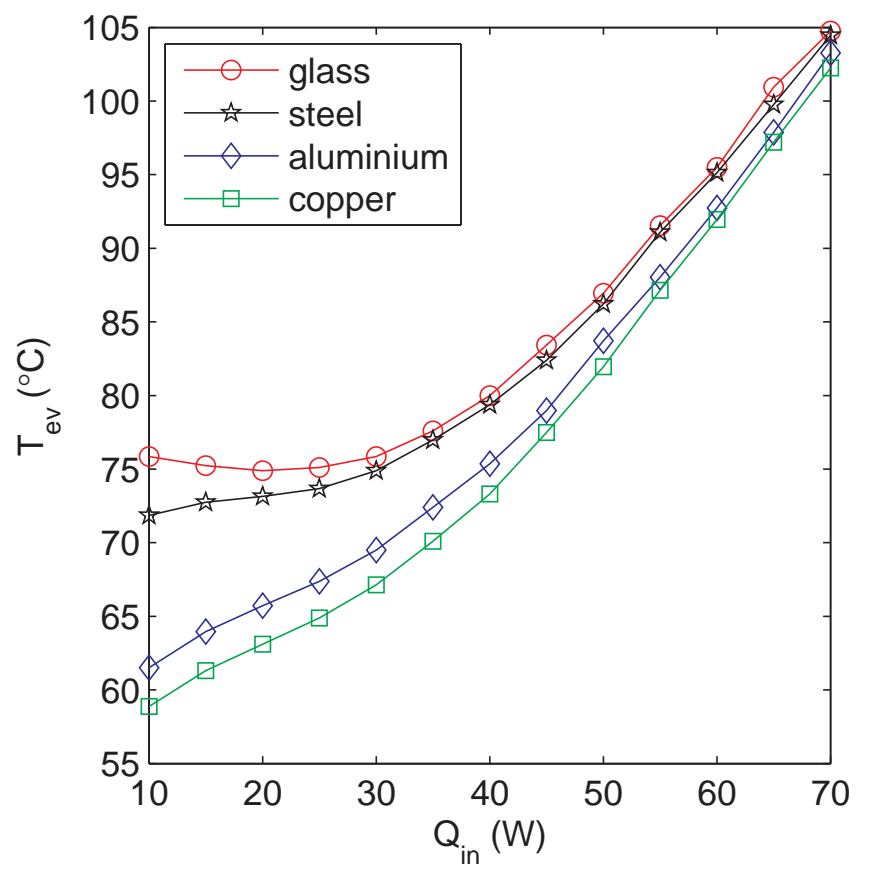

Figure 8: Influence of the transport lines thermal conductivity on the LHP operating temperature

exit of the condenser $(x=0.2 \mathrm{~m})$ is close to the heat sink temperature (Fig. 9). The vapour superheat is limited at the exit of the vapour grooves and the vapour line wall is cooled down by the heat losses to the ambient. Therefore, the vapour already condensates in the vapour line $(x=0.02 \mathrm{~m})$ before entering in the condenser. Then, the fluid temperature is equal to the saturation temperature and the high internal heat transfer coefficient tends to impose the temperature of the vapour to the wall until the entrance of the condenser. In the part of the condenser filled with liquid, both the wall and liquid temperatures decrease to reach the heat sink temperature.

In the case of a copper liquid line, a significant length of the tube wall is heated by conduction from the reservoir casing. The liquid returning to the compensation chamber is then at a higher temperature $T_{\text {res,in }}$, providing a very low subcooling. Since the liquid returning to the condenser is subcooled, a large amount of heat is conducted from the evaporator through the liquid line to be dissipated in contact with the liquid flowing in the tube. This effect is increased in variable conductance mode because the liquid exits the condenser at a temperature close to the heat sink temperature, thus providing a larger subcooling. In the case of a glass tube, heat conduction in the transport line wall is almost negligible and the liquid line wall is colder than with a copper line. As a result, the heat losses to the ambient decrease and the LHP operating temperature is higher.

At high heat loads, the vapour front is at the very end of the condenser (Fig. 10). Thus, the liquid length in the condenser is very small and the liquid temperature cannot reach the heat sink temperature. The rapid 


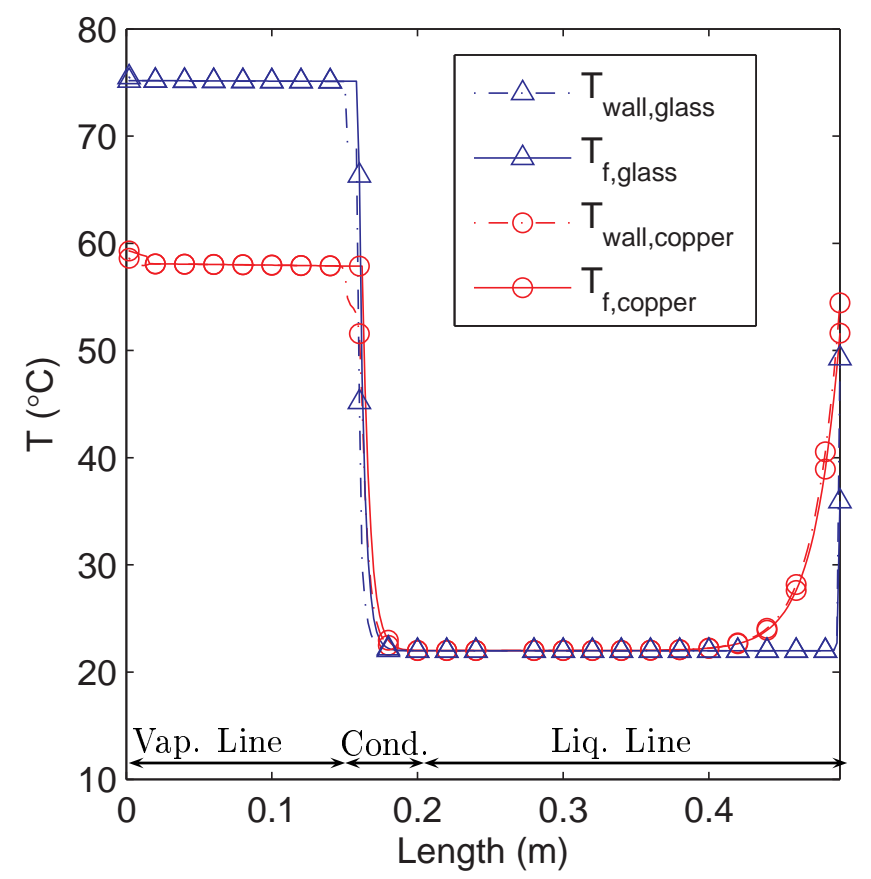

Figure 9: Temperature along the transport lines for $Q_{\text {in }}=10 \mathrm{~W}$

decrease of the wall temperature at the end of the condenser is due to the sharp variation of heat transfer coefficient between the fluid and the tube. At the beginning of the condenser, the condensation phenomena tends to impose the temperature of the vapour to the wall. At the end of the condenser, the heat transfer coefficient with the liquid is much smaller, and thus the heat sink tends to impose its temperature to the wall. As a result, the temperature of the liquid decreases at the end of the condenser. In the liquid line, the wall and the liquid flowing in the tube reach approximately the same temperature and, as a consequence of heat losses to the ambient, the temperature decreases along the liquid line. The liquid is heating up before entering the reservoir, due to heat conduction from the reservoir casing. Thus, the wall and the liquid temperatures are closer to the reservoir temperature than at low heat loads and the transport line material has a minor influence, the liquid subcooling being almost constant whatever the conduction in the tubes.

\subsection{Wick thermal conductivity and thickness}

Heat fluxes through the wick being significant for the LHP operation, several wick materials have been compared, neglecting the heat transfer through the evaporator body and the heat losses to the ambient (Fig. 11).

The results show that in the variable conductance mode, a decrease of the wick thermal conductivity leads to higher system temperatures only for medium and high-conductivity materials, whereas for less conductive 


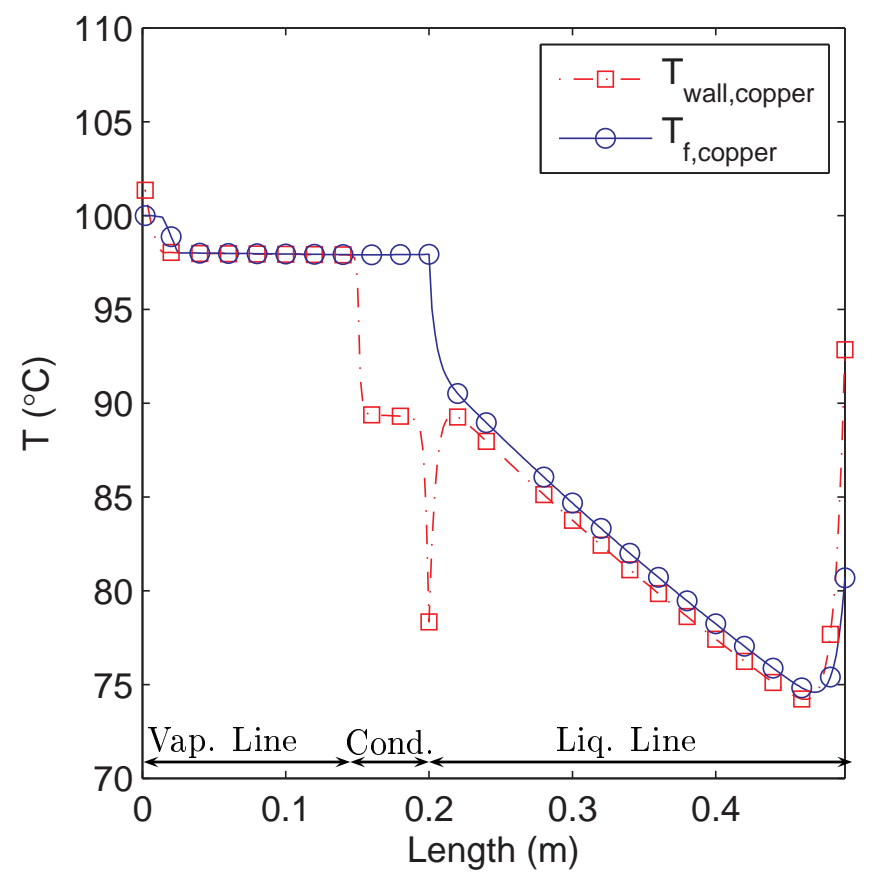

Figure 10: Temperature along the transport lines for $Q_{\text {in }}=70 \mathrm{~W}$

materials such as plastics or ceramics, an opposite effect is observed. At high heat loads, the effect of the wick material is less pronounced. Such an extremum is the consequence of two opposite phenomena. Decreasing the wick conductivity reduces the part of heat passing through the porous structure, thus leading to a lower transversal parasitic heat flux. The subcooling of the liquid entering the reservoir is then reduced and the LHP operates at a lower temperature. At the same time, a more conductive porous structure enhances the evaporation at the wick surface in contact with the vapour groove. When the evaporation heat transfer at the contact line between the fin, the groove and the wick is limited (small value of $a_{\mathrm{ev}}$ ) or when a high thermal contact resistance exists between the fin and the porous material, heat has to be conducted through a longer path in the wick in order to be evaporated. In that case, a lower conductivity can decrease the evaporation rate and leads to higher LHP temperatures.

Figure 12 presents the non-dimensional heat transfer rates (defined as the ratio between the rate of heat flow and its maximal value) in the evaporator as a function of the porous material thermal conductivity. An extremum is found for a thermal conductivity $\lambda_{\mathrm{w}}$ of $10 \mathrm{~W} \cdot \mathrm{m}^{-1} \cdot \mathrm{K}^{-1}$, i.e. an effective thermal conductivity of the wick $\lambda_{\text {eff }}$ equal to $2 \mathrm{~W} \cdot \mathrm{m}^{-1} \cdot \mathrm{K}^{-1}$. Above that value, the evaporation rate $Q_{\mathrm{ev}}^{*}$ is enhanced by a more conductive wick because conduction in the porous structure is improved near the evaporation zone. This effect overcomes the capacity of the wick to transfer the total parasitic heat flux $Q_{\text {par }}^{*}$ to the reservoir 


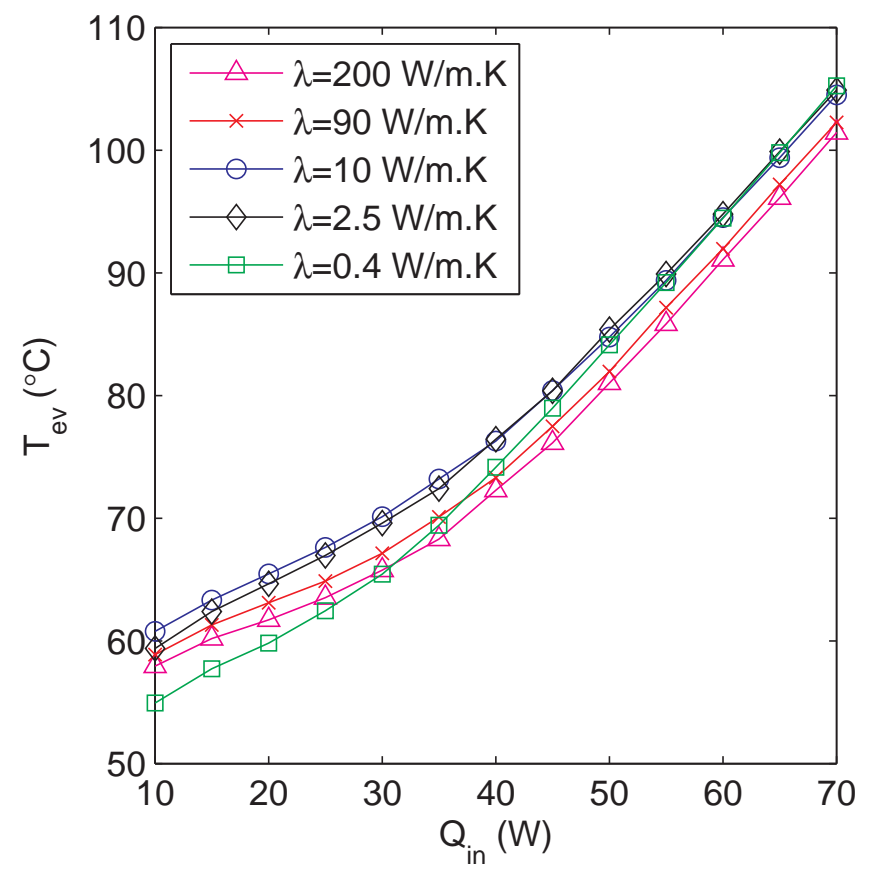

Figure 11: Influence of the wick material conductivity on the LHP operating temperature - $Q_{\text {wall }}$ and $Q_{\text {amb }}$ neglected

by conduction. For lower thermal conductivities, heat leaks through the porous material are considerably reduced. Thus, heat is preferentially dissipated by evaporation at the wick surface and this leads to better performance.

The competition between these two effects is particularly observed when the evaporation rate close to the fin is limited. This is confirmed by Figure 13 where the non-dimensional evaporation rate is plotted as a function of the wick material conductivity, for several evaporation coefficients $a_{\mathrm{ev}}$. With a higher evaporation coefficient, a larger part of the total evaporated mass flow rate takes place at the surface of the liquid film close to the fin. In such a case, the wick conductivity has less influence on the evaporation rate and the extremum is found for materials having a high thermal conductivity. Therefore, the wick thermal conductivity should be as low as possible to block the parasitic heat flux through the wick.

The same simulations have been realized considering longitudinal heat losses and heat losses to the ambient. Non-dimensional heat transfer rates are presented in Figure 14. When the heat losses to the ambient and through the evaporator casing cannot be neglected, no extremum can be found.

When the thermal conductivity of the porous structure is low, the evaporation transfer rate and the sensible heat given to the liquid in the wick are lower. At the same time, although the heat transfer through the wick decreases, parasitic heat losses increase due to the conduction in the evaporator casing. These phenomena lead to a much higher operational temperature when the wick thermal conductivity is low.

From these results, several situations emerge. In order to ensure good LHP performance when the 


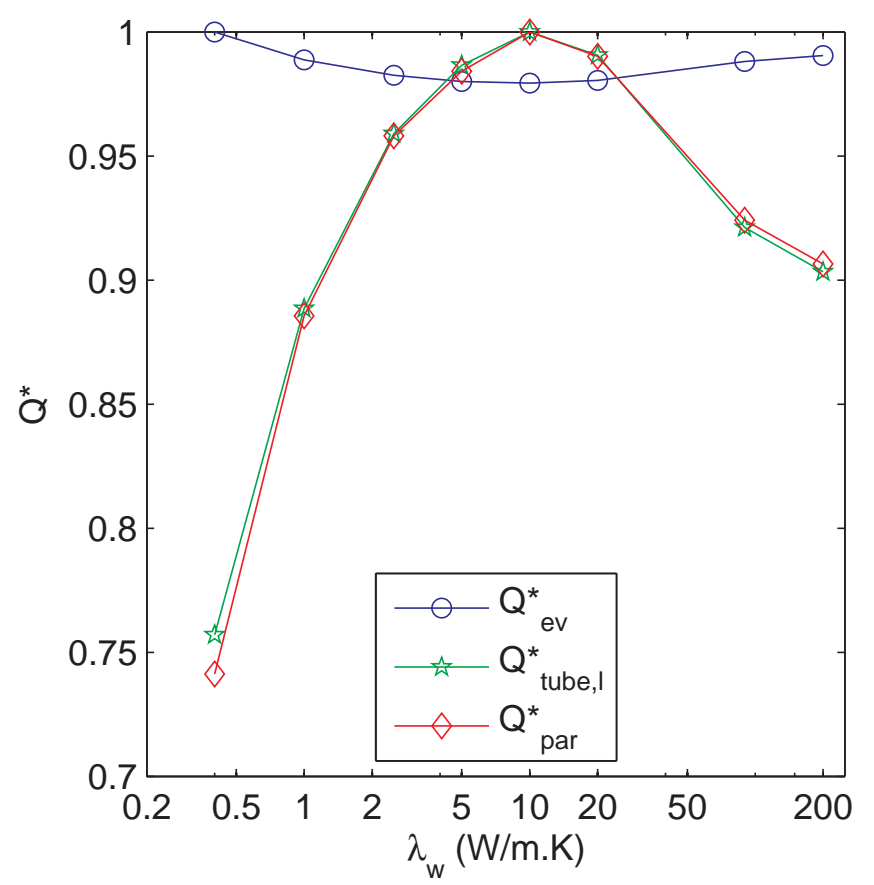

Figure 12: Influence of the wick thermal conductivity on the LHP performance - $Q_{\text {wall }}$ and $Q_{\text {amb }}$ neglected

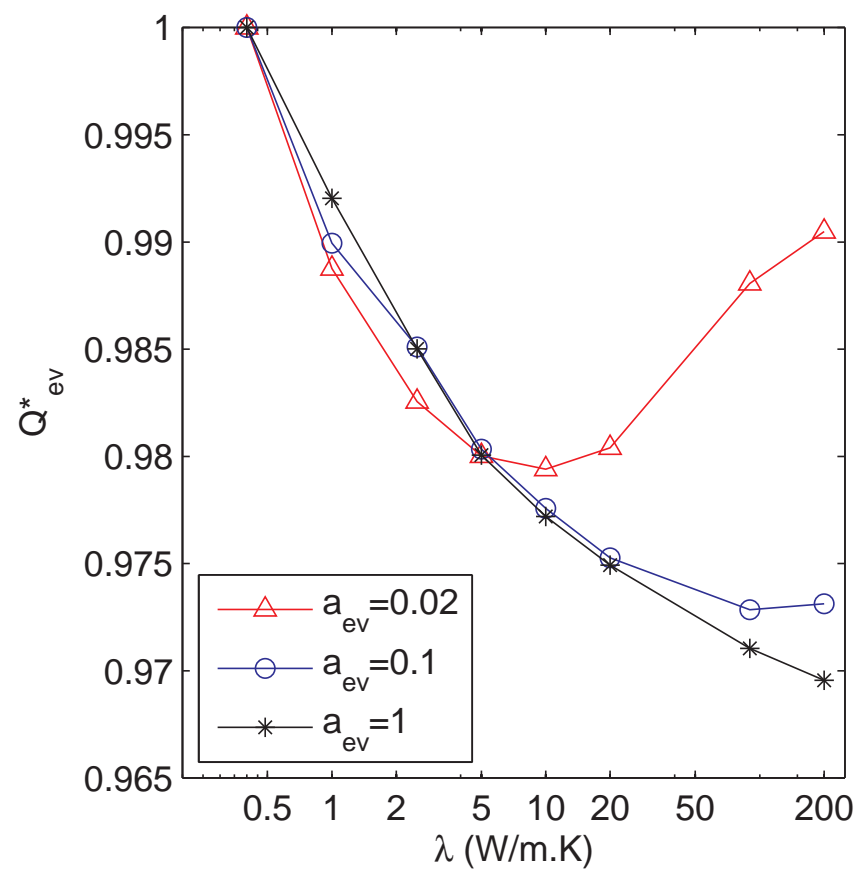

Figure 13: Influence of the evaporation coefficient on $Q_{\mathrm{ev}}^{*}$ 


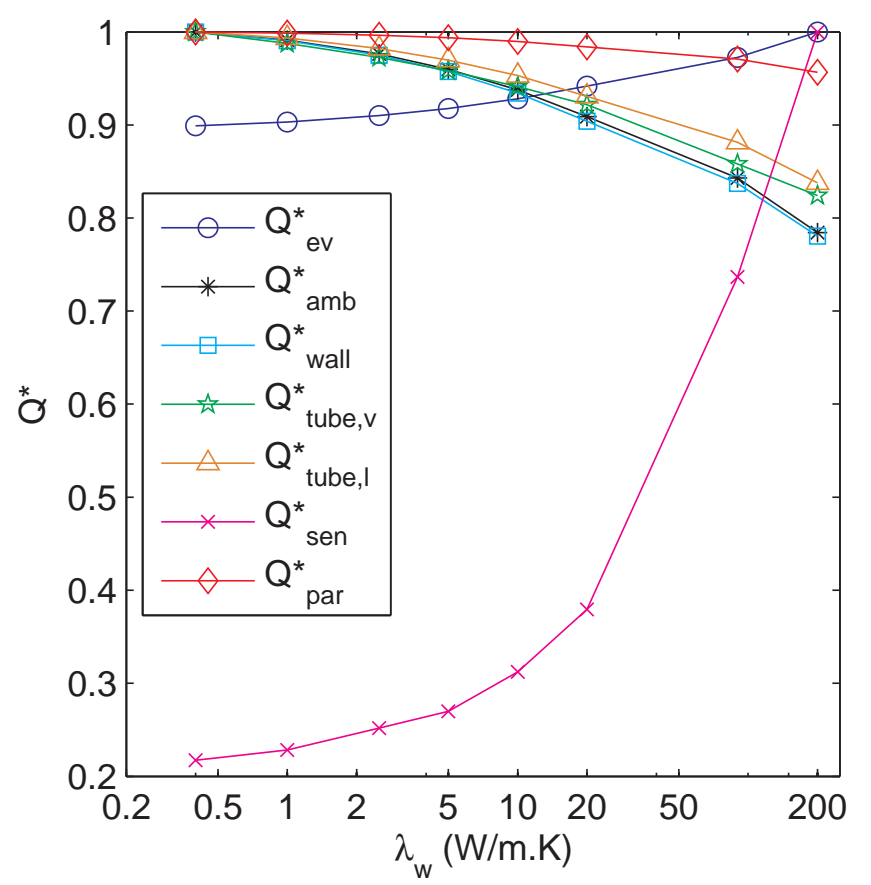

Figure 14: Influence of the wick thermal conductivity on the LHP performance considering heat losses

longitudinal parasitic heat losses can be neglected (insulated LHP with low-conductivity evaporator casing), one has to avoid selecting a material in a medium conductivity range for the wick. The use of a biporous wick or a secondary wick with lower conductivity can also help reducing heat leaks without lowering the evaporation rate. Likewise, thicker wicks can prevent heat from passing through the porous structure to the reservoir (Fig. 15) and are less susceptible to deprime in the case of an evaporation front displacement in the wick. However, a compromise has to be found, since a greater wick thickness leads to higher pressure drops and can be limited by the space available for the integration of the evaporator. When the longitudinal heat losses are determinant, one should rather choose a wick made from a good thermal conductive material to ensure a good evaporation rate.

\subsection{Heat transfer in the evaporator}

Figure 16 presents the different components of the heat flux in the evaporator divided by the total heat load $Q_{\text {in }}$, without considering longitudinal heat losses. The $2 \mathrm{~mm}$ thick evaporator casing is made of copper and the loop is not insulated. A nickel wick is considered, with an effective thermal conductivity $\lambda_{\text {eff }}$ equal to $5.4 \mathrm{~W} \cdot \mathrm{m}^{-1} \cdot \mathrm{K}^{-1}$. More than $90 \%$ of the heat is dissipated by evaporation $Q_{\mathrm{ev}}$ while 2 to $10 \%$ is transferred through the liquid line $Q_{\text {tube,1. }}$. The parasitic heat flux through the wick $Q_{\text {par }}$ is equal to about $3 \%$ of the total heat load. The other heat transfer rates are less than $1 \%$, confirming that more heat is conducted through the liquid line than through the vapour line. It appears also that when the heat load increases, the 


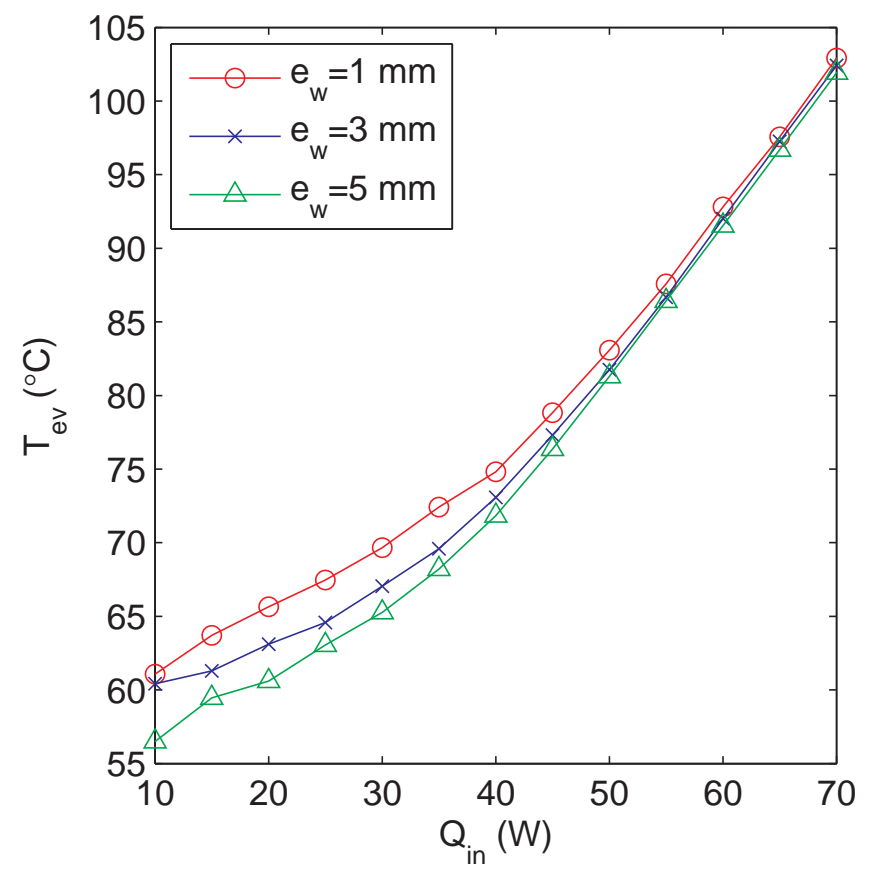

Figure 15: Influence of the wick thickness - $Q_{\text {wall }}$ and $Q_{\text {amb }}$ neglected

evaporation rate is enhanced and heat losses through the liquid line are less significant.

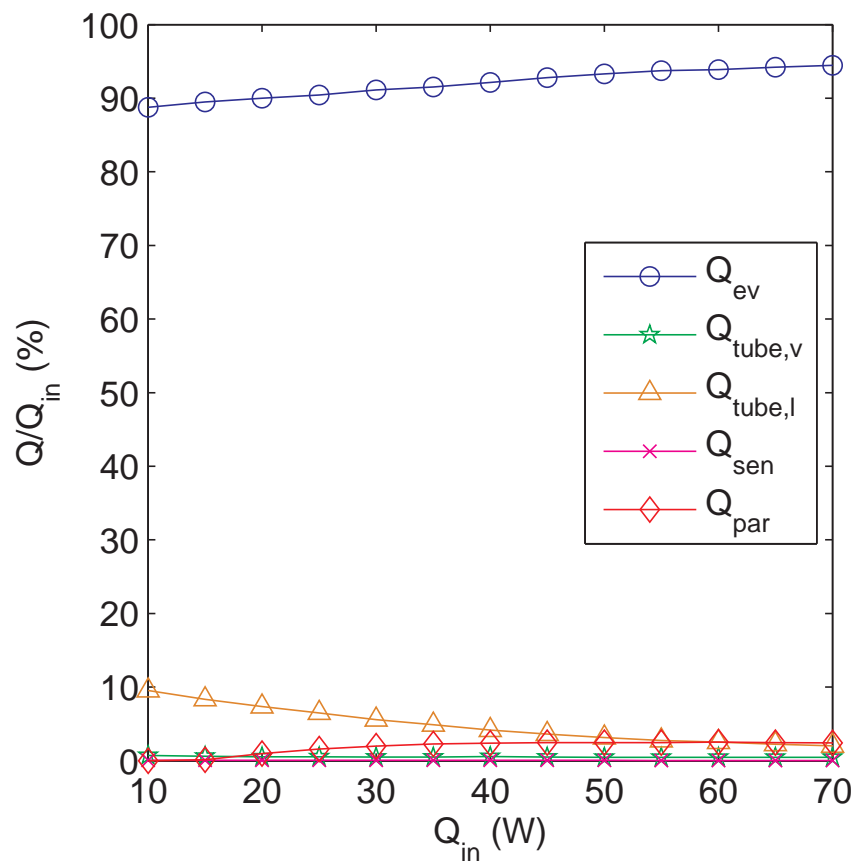

Figure 16: Heat transfer in the LHP - $Q_{\text {wall }}$ and $Q_{\text {amb }}$ neglected 
When $Q_{\text {wall }}$ and $Q_{\text {amb }}$ are taken into account, heat transfer inside the evaporator are very different (Fig. 17). In that case, the evaporation heat transfer rate $Q_{\mathrm{ev}}$ ranges from 55 to $70 \%$. Since the reservoir temperature is higher, heat losses through the liquid line $Q_{\text {tube,1 }}$ are larger (10 to 20\%). $Q_{\text {amb }}$ represents the heat losses to the ambient from the reservoir and the evaporator and its value is up to $20 \%$ of the total heat flux. The total parasitic heat flux $Q_{\mathrm{par}}$ is more important considering the heat transfer by conduction through the evaporator body $\left(Q_{\text {wall }}=2-5 \%\right.$ ) and leads to a value of 2 to $15 \%$. Heat losses to the ambient are less dominant for high heat loads whereas the total parasitic heat flux and the evaporation rate are enhanced.

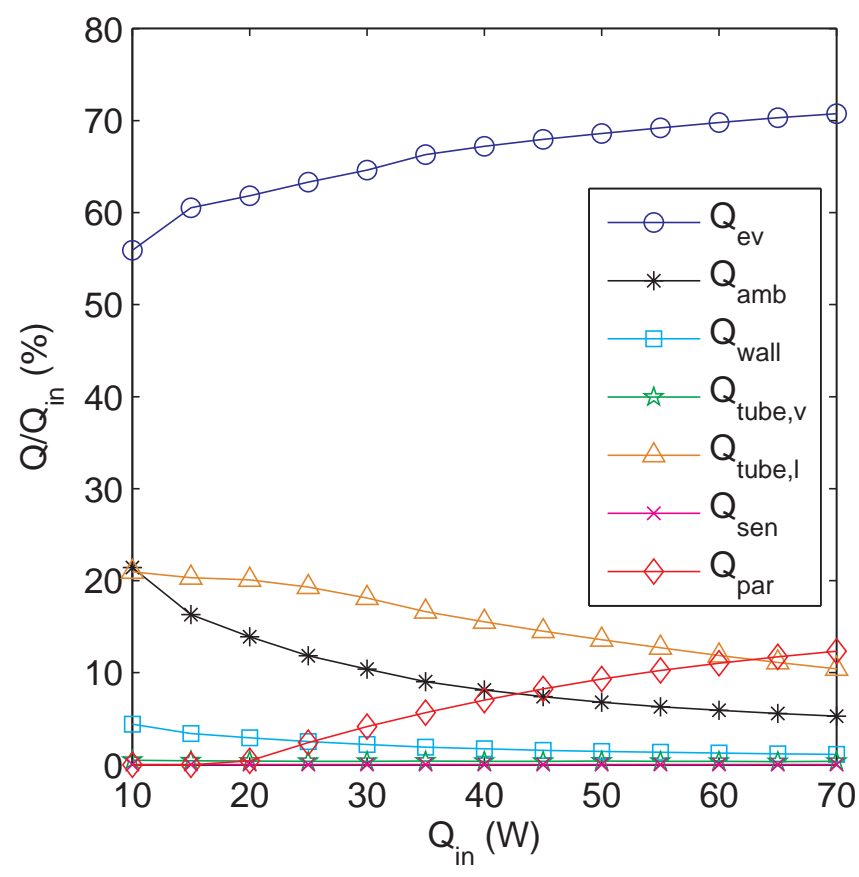

Figure 17: Heat transfer in the LHP considering heat losses

\subsection{Evaporator body material and thickness}

Two casing materials with a body thickness equal to $2 \mathrm{~mm}$ have been tested in order to determine the influence of the outer wall thermal conductivity on the evaporator temperature (Fig. 18). Additionally, a copper evaporator with a thinner wall $\left(e_{\text {wall }}=1 \mathrm{~mm}\right)$ has been simulated and all the results have been compared to the modelling without heat losses. Indeed, the parasitic heat flux from the saddle to the reservoir, as well as the heat exchange with the ambient can be strongly dependent on these parameters. The other geometrical and ambient characteristics of the modelling are presented in Section 3.

The choice of a very low thermal conductivity material such as PEEK $\left(\lambda_{\text {wall }}=0.25 \mathrm{~W} \cdot \mathrm{m}^{-1} \cdot \mathrm{K}^{-1}\right)$ considerably reduces the heat flux through the evaporator sidewall on the LHP operation. The simulations 


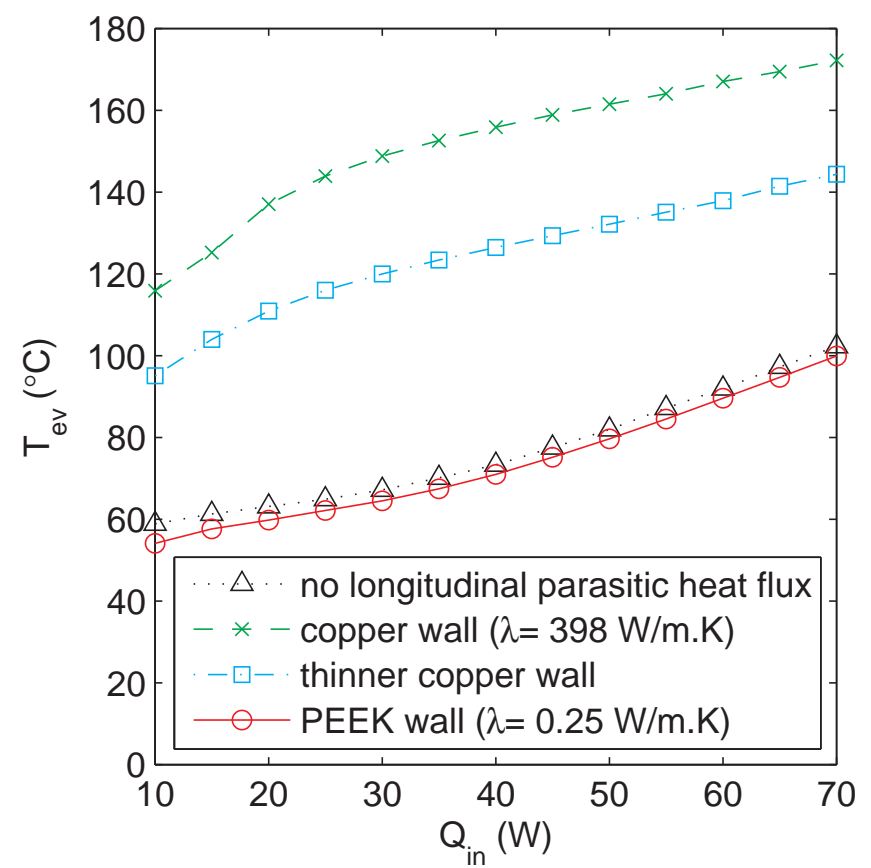

Figure 18: Influence of the evaporator sidewall conductivity and thickness

results are very close to the solution without considering the longitudinal parasitic heat flux. However, heat losses to the ambient decrease the evaporator temperature. The use of a very conductive material such as copper $\left(\lambda_{\text {wall }}=398 \mathrm{~W} \cdot \mathrm{m}^{-1} \cdot \mathrm{K}^{-1}\right)$ strongly affects the LHP operational temperature, because the parasitic heat flux through the evaporator sidewall is increased. This phenomena is more pronounced when the casing is thicker, since the cross-sectional area for the conductive heat transfer is larger.

\subsection{Heat losses to the ambient}

Although LHP are not insulated in usual applications, one can find in the literature many experiments with the tubes or the whole loop insulated. The purpose of this is to minimize heat losses to the ambient, often difficult to evaluate, in order to ease the model validation or to characterize the LHP performance without taking into account the environment influence. Figure 19 presents the comparison of the evaporator temperature with and without glass-fibre insulation on the evaporator-reservoir structure. The results clearly show that without insulation, the LHP performance are enhanced. Indeed, whatever the heat load, heat losses to the ambient cool the system and can be of great importance in the LHP heat balance. In the case of a low conductive evaporator casing, the influence of the insulation is less noticeable because the evaporator body itself prevents heat from being conducted to the evaporator side and thus decreases heat losses to the ambient. 


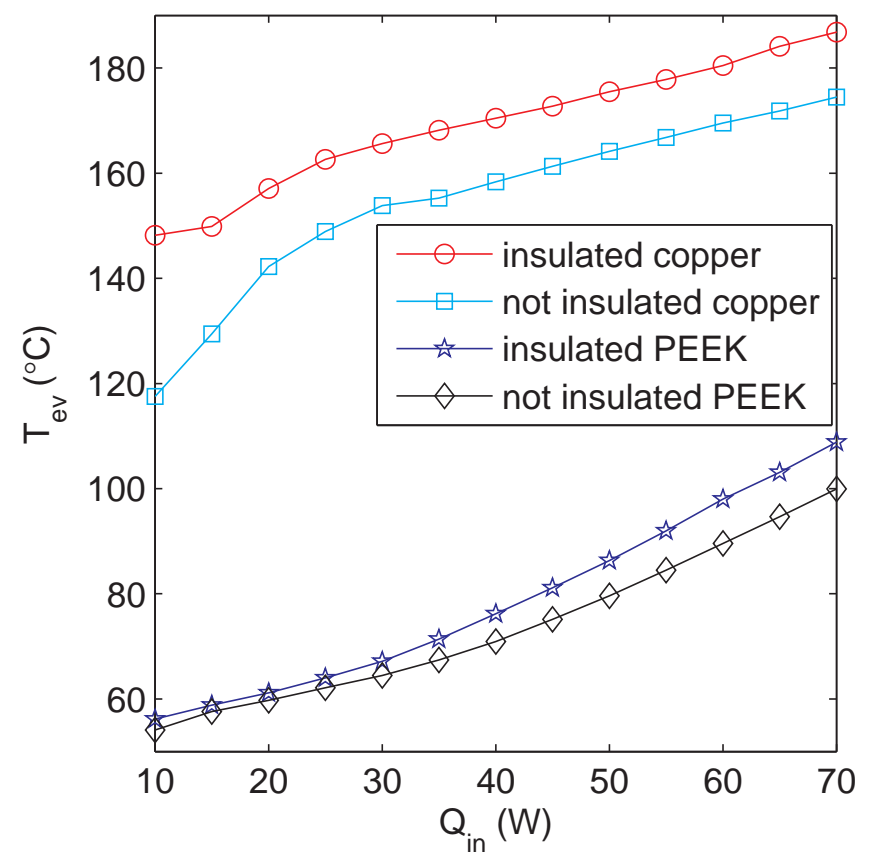

Figure 19: Influence of the insulation on the LHP operating temperature

\section{Conclusion}

In this study, a complete model of LHP has been presented. It combines a 2-D description of the evaporator hydraulic and thermal states with a fine discretization of the transport lines and the condenser. These original features enable to take into account heat losses to the ambient and through the transport lines as well as to evaluate the parasitic heat flux through the wick and the evaporator body. The present numerical simulations may improve the understanding of the physical mechanisms operating in an LHP evaporator, and their coupling with the other parts of the LHP, and provide guidance for the LHP design, aiming to reduce the thermal resistance of the system.

The model has been confronted to a set of experimental data from the literature. A good agreement is found between experimental and theoretical results for the entire heat input range.

Heat transfer through the transport lines has to be taken into account, in particular in variable conductance mode, since it can modify significantly the subooling of the liquid entering the reservoir.

Simulations show the major influence of the evaporation coefficient and of the wick conductivity on the LHP operating temperature as well as on the temperature field in the evaporator. When the effect of the heat transfer through the evaporator casing is insignificant, the competition between the parasitic heat flux through the wick and the heat transfer to the evaporation zone leads to an extremum for which the operating temperature is maximal. Additionally, a low evaporation coefficient leads to a significant increase of the loop operating temperature. 
Parasitic heat losses through the evaporator casing strongly affect the energy balance of the evaporator and lead to a major decrease of the evaporation rate. As a result, a much larger operating temperature is found in the case of substantial heat conduction in the evaporator body.

\section{Acknowledgements}

The authors want to acknowledge the financial support of the European Commission through the FP7 PRIMAE Project, Contract n. 265413 (www.primae.org).

\section{Nomenclature}

$\begin{array}{lll}A & \text { cross-sectional area } & {\left[\mathrm{m}^{2}\right]} \\ a_{\mathrm{ev}} & \text { evaporation coefficient } & \\ c_{\mathrm{p}} & \text { specific heat } & {\left[\mathrm{J} \cdot \mathrm{kg}^{-1} \cdot \mathrm{K}^{-1}\right]} \\ e & \text { thickness } & {[\mathrm{m}]} \\ D & \text { diameter } & {[\mathrm{m}]} \\ g & \text { gravitational acceleration } & {\left[\mathrm{m} . \mathrm{s}^{-2}\right]} \\ H & \text { height } & {[\mathrm{m}]} \\ h & \text { convective heat transfer coefficient } & {\left[\mathrm{W}^{-\mathrm{m}^{-2}} \cdot \mathrm{K}^{-1}\right]} \\ h_{\mathrm{lv}} & \text { enthalpy of vaporization } & {\left[\mathrm{J} \cdot \mathrm{kg}^{-1}\right]} \\ K_{\mathrm{w}} & \text { wick permeability } & {\left[\mathrm{m}^{2}\right]} \\ L & \text { flow entry length } & {[\mathrm{m}]} \\ \bar{M} & \text { molar mass } & {\left[\mathrm{kg} \cdot \mathrm{mol}^{-1}\right]} \\ \dot{m} & \text { mass flow rate } & {\left[\mathrm{kg} \cdot \mathrm{s}^{-1}\right]} \\ p & \text { perimeter } & {[\mathrm{m}]} \\ P & \text { pressure } & {[\mathrm{Pa}]} \\ Q & \text { heat transfer rate } & {[\mathrm{W}]} \\ Q^{*} & \text { non-dimensional heat transfer rate } & \\ \bar{R} & \text { universal gas constant } & {\left[\mathrm{J} . \mathrm{K}^{-1} \cdot \mathrm{mol}^{-1}\right]} \\ r_{\mathrm{p}} & \text { pore radius } & {[\mathrm{m}]} \\ T & \text { temperature } & {[\mathrm{K}]} \\ u & \text { velocity } & {\left[\mathrm{m} . \mathrm{s}^{-1}\right]} \\ x & \text { quality, axis coordinate } & {[\mathrm{m}]} \\ y, z & \text { axis coordinates } & \end{array}$

Greek Symbols 


$\begin{array}{lll}\rho & \text { density } & {\left[\mathrm{kg} \cdot \mathrm{m}^{-3}\right]} \\ \lambda & \text { thermal conductivity } & {\left[\mathrm{W} \cdot \mathrm{m}^{-1} \cdot \mathrm{K}^{-1}\right]} \\ \varepsilon & \text { void fraction, porosity } & \\ \mu & \text { dynamic viscosity } & {[\mathrm{Pa} \cdot \mathrm{s}]} \\ \chi_{\mathrm{tt}} & \text { Martinelli parameter } & \\ \phi & \text { heat flux density } & {\left[\mathrm{W} \cdot \mathrm{m}^{-2}\right]}\end{array}$

Subscripts 


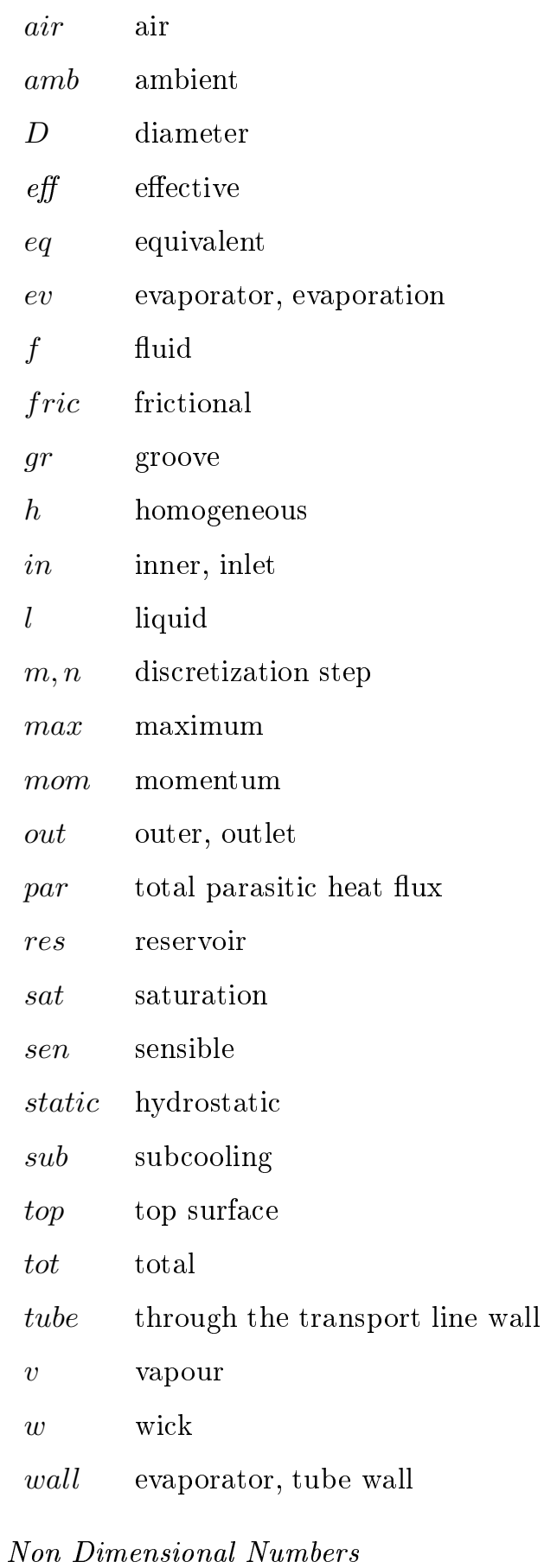

Non Dimensional Numbers 

$\mathrm{Fr} \quad$ Froude number
Ga Galileo number
Gz Graetz number
Pr Prandtl number
$R a \quad$ Rayleigh number
Re Reynolds number

\section{References}

[1] J. Ku, Operating characteristics of loop heat pipes, in: $29^{t h}$ International Conference on Environmental System, no. 1999-01-2007, 1999.

[2] S. Launay, V. Sartre, J. Bonjour, Parametric analysis of loop heat pipe operation: a literature review, International Journal of Thermal Sciences 46 (7) (2007) 621-636.

[3] T. Kaya, J. Ku, T. T. Hoang, M. K. Cheung, Mathematical modeling of loop heat pipes, in: $37^{\text {th }}$ AIAA Aerospace Sciences Meeting and Exhibit, no. 477, 1999.

[4] A. Adoni, A. Ambirajan, V. Jasvanth, D. Kumar, P. Dutta, Theoretical studies of hard filling in loop heat pipes, Journal of Thermophysics and Heat Transfer 24 (1) (2010) 173-183.

[5] P. Chuang, An improved steady-state model of loop heat pipes based on experimental and theoretical analyses, Ph.D. thesis, Pennsylvania State University, USA (2003).

[6] S. Launay, V. Sartre, J. Bonjour, Analytical model for characterization of loop heat pipes, Journal of Thermophysics and Heat Transfer 22 (4) (2008) 623-631.

[7] L. Bai, G. Lin, H. Zhang, D. Wen, Mathematical modeling of steady-state operation of a loop heat pipe, Applied Thermal Engineering 29 (2009) 2643-2654.

[8] Y. Cao, A. Faghri, Analytical solutions of flow and heat transfer in a porous structure with partial heating and evaporation on the upper surface, International Journal of Heat and Mass Transfer 37 (10) (1994) 1525-1533.

[9] C. Figus, Y. Le Bray, S. Bories, M. Prat, Heat and mass transfer with phase change in a porous structure partially heated: continuum model and pore network simulations, International Journal of Heat and Mass Transfer 42 (1999) 1446-1458.

[10] T. Coquard, Coupled heat and mass transfer in an element of a capillary evaporator (in french), Ph.D. thesis, Institut National Polytechnique de Toulouse, France (2006).

[11] T. Zhao, Q. Liao, On capillary-driven flow and phase-change heat transfer in a porous structure heated by a finned surface: measurements and modeling, International Journal of Heat and Mass Transfer 43 (7) (2000) 1141-1155.

[12] C. Ren, Q. Wu, M. Hu, Heat transfer in loop heat pipe's wick: Effect of porous structure parameters, Journal of Thermophysics and Heat Transfer 21 (4) (2007) 702-711.

[13] M. A. Chernysheva, Y. F. Maydanik, 3D-model for heat and mass transfer simulation in flat evaporator of copper-water loop heat pipe, Applied Thermal Engineering 33-34 (2012) 124-134.

[14] N. Rivière, V. Sartre, J. Bonjour, Fluid mass distribution in a loop heat pipe with flat evaporator, in: $15^{\text {th }}$ International Heat Pipe Conference, no. 4-1, Clemson, USA, 2010.

[15] H. Müller-Steinhagen, K. Heck, A simple friction pressure drop correlation for two-phase flow in pipes, Chemical Engineering and Processing: Process Intensification 20 (6) (1986) 297-308.

[16] J. R. Thome, Engineering Data Book III, Wolverine Tube Inc., WebBook, 2006.

[17] S. W. Churchill, H. H. Chu, Correlating equations for laminar and turbulent free convection from a horizontal cylinder, International Journal of Heat and Mass Transfer 18 (9) (1975) 1049-1053. 
[18] F. P. Incropera, D. P. DeWitt, Fundamentals of heat and mass transfer, John Wiley \& Sons, New York, USA, 1996.

[19] M. Miscevic, P. Lavieille, B. Piaud, Numerical study of convective flow with condensation of a pure fluid in capillary regime, International Journal of Heat and Mass Transfer 52 (21-22) (2009) 5130-5140.

[20] H. M. Soliman, On the annular-to-wavy flow pattern transition during condensation inside horizontal tubes, The Canadian Journal of Chemical Engineering 60 (4) (1982) 475-481.

[21] J. G. Collier, J. R. Thome, Convective boiling and condensation, $3^{\text {rd }}$ edition, Oxford University Press, Oxford, UK, 1994.

[22] M. K. Dobson, J. C. Chato, Condensation in smooth horizontal tubes, Journal of Heat Transfer 120 (1998) 193.

[23] W. W. Akers, H. A. Deans, O. K. Crosser, Condensing heat transfer within horizontal tubes, Chemichal Engineering Progress Symposium Series 59 (29) (1958) 171-176.

[24] M. A. Hanlon, H. B. Ma, Evaporation heat transfer in sintered porous media, Journal of Heat Transfer 125 (4) (2003) $644-652$.

[25] R. Singh, A. Akbarzadeh, M. Mochizuki, Effect of wick characteristics on the thermal performance of the miniature loop heat pipe, Journal of Heat Transfer 131 (8) (2009) 082601.

[26] J. Choi, Y. Lee, B. Sung, C. Kim, Investigation on operational characteristics of the miniature loop heat pipes with flat evaporators based on diverse vapor removal channels, in: $16^{\text {th }}$ International Heat Pipe Conference, no. 023, Lyon, France, 2012.

[27] V. P. Carey, Liquid-vapor phase-change phenomena, Hemisphere, New York, USA, 1992.

[28] I. Eames, N. Marr, H. Sabir, The evaporation coefficient of water: a review, International Journal of Heat and Mass Transfer 40 (12) (1997) 2963-2973.

[29] R. Singh, A. Akbarzadeh, M. Mochizuki, Operational characteristics of a miniature loop heat pipe with flat evaporator, International Journal of Thermal Sciences 47 (2008) 1504-1515. 